\title{
ARL13B regulates Sonic Hedgehog signaling from outside primary cilia
}

\author{
Eduardo D. Gigante ${ }^{a, b}$, Megan R. Taylor ${ }^{c}$, Anna A. Ivanovad, Richard A. Kahn ${ }^{d}$, Tamara \\ Caspary
}

aNeuroscience Graduate Program, bepartment of Human Genetics, "Emory College of Arts and Sciences, ${ }^{d}$ Department of Biochemistry, Emory University School of Medicine, Atlanta, GA 30322, USA

Author e-mails: Eduardo.gigante@emory.edu,meg96taylor@gmail.com, anna.ivanova@emory.edu, rkahn@emory.edu

ORCID ID: Gigante: 0000-0002-1486-5377, Kahn: 0000-0002-0259-0601, Caspary:

0000-0002-6579-7589

HCorrespondence: Tamara Caspary

tcaspar@emory.edu 


\section{Abstract}

ARL13B is a regulatory GTPase highly enriched in cilia. Complete loss of $\mathrm{Arl13b}$

2 disrupts cilia architecture, protein trafficking and Sonic hedgehog signaling. To

3 determine whether ARL13B is required within cilia, we knocked in a cilia-excluded

4 variant of $A R L 13 B(V 358 A)$ and showed it retains all known biochemical function. We

5 found that $A R L 13 B^{V 358 A}$ protein was expressed but could not be detected in cilia, even

6 when retrograde ciliary transport was blocked. We showed Arl13bV358A/V358A mice are

7 viable and fertile with normal Shh signal transduction. However, in contrast to wild type

8 cilia, Arl13bV358A/V358A cells displayed short cilia and lacked ciliary ARL3 and INPP5E.

9 These data indicate that ARL13B's role within cilia can be uncoupled from its function

10 outside of cilia. Furthermore, these data imply that the cilia defects upon complete

11 absence of ARL13B do not underlie the alterations in Shh transduction, which is

12 unexpected given the requirement of cilia for Shh transduction.

\section{Keywords:}

ARL13B; Sonic Hedgehog signaling; primary cilia; mouse development 


\section{Introduction}

The Hedgehog $(\mathrm{Hh})$ signaling pathway is essential for embryogenesis in a wide

14 variety of organisms. Initially discovered in Drosophila where there is a single Hh ligand,

15 the core components of the Hh pathway are conserved in vertebrates (Nusslein-Volhard

16 et al. 1980). These include the vertebrate Hh receptor Patched1 (Ptch1), the obligate

17 transducer of the pathway Smoothened (Smo), as well as the Gli transcription factors

18 (Ci in Drosophila) that act as both activators (GliA) and repressors (GliR) to control

19 target gene transcription (Briscoe et al. 2013). There are three Hh ligands in

20 vertebrates, Sonic (Shh), Indian (Ihh) and Desert (Dhh), that regulate a multitude of

21 developmental processes including formation of the limbs and digits, the bones of the

22 skull and face, and the patterning of the neural tube (Placzek et al. 2018). Diminished

23 Hh signaling during embryogenesis results in birth defects whereas increased $\mathrm{Hh}$

24 signaling leads to tumors, highlighting the importance of the pathway and its regulation

25 (Raleigh et al. 2019).

Given the deep homology between invertebrate and vertebrate Hh signaling, the

27 discovery that primary cilia are required for vertebrate, but not invertebrate, Hh signaling

28 was unexpected (Huangfu et al. 2003; Huangfu et al. 2006). Vertebrate Hh components

29 dynamically traffic within primary cilia in response to Hh ligand (Corbit et al. 2005;

30 Haycraft et al. 2005; Rohatgi et al. 2007). In the absence of ligand, Ptch1 is enriched on

31 the ciliary membrane and Smo is barely detectable (Corbit et al. 2005; Rohatgi et al.

32 2007). Furthermore, full length Gli proteins traffic to the ciliary tip and back to the

33 cytoplasm before being cleaved to their repressor form, which actively shuts down Hh

34 target gene transcription in the nucleus (Kim et al. 2009; Liu et al. 2005; Wen et al. 
35 2010; Humke et al. 2010). In contrast, upon ligand stimulation (Shh, Ihh or Dhh), the

36 Ptch1 receptor binds the ligand and shuttles out of cilia (Rohatgi et al. 2007).

37 Subsequently, Smo is enriched in the cilium and is subsequently activated (Kong et al.

38 2019; Corbit et al. 2005). Activated Smo promotes the processing of full-length Gli

39 transcription factors into GliA, which turns on target genes (Aza-Blanc et al. 2000; Ruiz i

40 Altaba 1998). Ablation of cilia results in an absence of GliA and GliR production,

41 rendering the pathway inert and leading to an absence of transcriptional response

42 (Huangfu et al. 2005). The dynamic ciliary movement of Shh components appears to be

43 critical to pathway function, as alterations to cilia disrupt pathway output (Caspary et al.

44 2007; Huangfu et al. 2006; Liem et al. 2012; Liem et al. 2009; Goetz et al. 2009;

45 Murdoch et al. 2010; Tuz et al. 2014; Cortellino et al. 2009; Houde et al. 2006; Liu et al.

46 2005; Tran et al. 2008; Taylor et al. 2015).

47 Given that the fundamental logic of the pathway is conserved from flies through

48 vertebrates, and that flies transduce Hh signals without relying on primary cilia, both

49 evolutionary and mechanistic questions are raised as to how vertebrate cells co-opted

50 the primary cilium for Hh signal transduction. One distinction lies in the fact that

51 vertebrates use Hh signaling over a longer distance than flies, leading to the proposal

52 that the primary cilium is a critical part of a mechanism underlying long range signaling

53 (Bangs et al. 2015). For example, in neural patterning Shh is initially expressed in the

54 notochord and is secreted to specify fates more than 20 cells away (Chiang et al. 1996;

55 Briscoe et al. 2001; Roelink et al. 1994). At the evolutionary level, comparisons among

56 organisms with cilia and or Hh have provided some clues. The round worm C. elegans

57 have cilia yet do not possess Hh signaling as they don't have most of the genes 
58 encoding the core components of Hh signal transduction (Consortium 1998; Roy 2012).

59 Curiously, a few components of Hh signaling such as fused and costal 2 are in the $C$.

60 elegans genome where they are functionally important for ciliogenesis (Ingham et al.

61 2011). Additionally, C. elegans retained a Ptch1 homolog important for development

62 and pattern formation, but no Hh or Smo (Zugasti et al. 2005; Kuwabara et al. 2000). In

63 contrast, planaria flatworms possess both cilia and Hh signaling but the cilia are not

64 required to transduce $\mathrm{Hh}$ signaling (Rink et al. 2009). The first known evolutionary link

65 between cilia and $\mathrm{Hh}$ is in sea urchins which transduce Hh signal in developing muscle

66 tissue via motile cilia (Warner et al. 2014; Sigg et al. 2017). Subsequently, in

67 vertebrates Hh signaling requires primary cilia. These data suggest that the mechanistic

68 link of cilia and $\mathrm{Hh}$ is limited to deuterostomes and raises the question of whether the

69 relationship of $\mathrm{Hh}$ and primary cilia originated near the last common ancestor of

70 vertebrates, the urochordates.

71 ARL13B is a member of the ARF family of regulatory GTPases and is highly

72 enriched on the ciliary membrane (Caspary et al. 2007). In mice, a null mutation of

73 Arl13b leads to short cilia and to alterations in Shh signal transduction (Caspary et al.

74 2007; Larkins et al. 2011). ARL13 is ancient, predicted to be present in the last common

75 eukaryotic ancestor. ARL13 appears to have been lost during evolution in organisms

76 that lack cilia and duplicated to $A R L 13 A$ and $A R L 13 B$ in the urochordates, thus $A R L 13 B$

77 is proposed to hold important clues in deciphering the links between primary cilia and

78 vertebrate Hh signaling (Schlacht et al. 2013; Li et al. 2004; Kahn et al. 2008; East et al.

79 2012; Logsdon et al. 2004). 
ARF regulatory GTPases, like ARL13B, are best known to play roles in

81 membrane trafficking (D'Souza-Schorey et al. 2006). As is true for a large number of

82 regulatory GTPases, ARL13B is functionally diverse (Sztul et al. 2019). It regulates

83 endocytic traffic (Barral et al. 2012), as well as the phospholipid composition of the

84 ciliary membrane through recruitment of the lipid phosphatase INPP5E to the ciliary

85 membrane (Humbert et al. 2012). ARL13B also has a conserved role as a guanine

86 nucleotide exchange factor (GEF) for ARL3, another ciliary ARF-like (ARL) protein

87 (Gotthardt et al. 2015; Zhang et al. 2016; Hanke-Gogokhia et al. 2016; Ivanova et al.

88 2017). ARL13B regulates intraflagellar transport (IFT), the process that builds and

89 maintains cilia (Cevik et al. 2010; Li et al. 2010; Nozaki et al. 2017). It is known to

90 interact with several proteins associated with cilia, including the exocyst, tubulin and

91 UNC119 (Seixas et al. 2016; Zhang et al. 2016; Larkins et al. 2011; Revenkova et al.

92 2018). Critical to this work, loss of ARL13B disrupts Shh signal transduction in at least

93 two distinct ways: Smo enrichment in cilia occurs even in the absence of ligand and Gli

94 activator production is diminished, although Gli repressor is made normally (Caspary et

95 al. 2007; Larkins et al. 2011).

96 Due to the high enrichment of ARL13B on the ciliary membrane, ARL13B is

97 assumed to function in its diverse roles from within the cilium. However, ARL13B is

98 present in early endosomes and circular dorsal ruffles on the cell surface (Barral et al.

99 2012; Casalou et al. 2014). We previously showed that a V358A variant of ARL13B

100 does not localize to cilia as it disrupts a known VxPx cilia localization sequence

101 (Higginbotham et al. 2012; Mariani et al. 2016). Exogenous overexpression of a

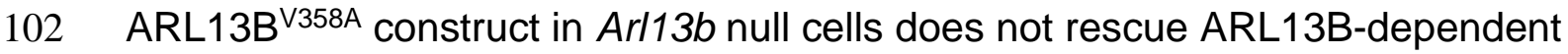


103 phenotypes such as cilia length as well as interneuron migration and connectivity,

104 consistent with ciliary ARL13B mediating these processes (Higginbotham et al. 2012;

105 Mariani et al. 2016). In contrast, we found that overexpressed ARL13B ${ }^{V 358 A}$ does rescue

106 the Shh-dependent ciliary enrichment of Smo in mouse embryonic fibroblasts, arguing

107 that ARL13B may function outside the cilium to regulate Smo traffic (Mariani et al.

108 2016). Together, these results raise the question of where ARL13B functions.

109 To define where ARL13B functions in relation to cilia, we wanted an in vivo

110 model so generated mice carrying the $A R L 13 B^{\mathrm{V} 358 \mathrm{~A}}$ point mutation using CRISPR/Cas9.

111 Here we demonstrate that $A R L 13 B^{V 358 A}$ protein was undetectable in $A r l 13 b^{V 358 A / V 358 A}$

112 cilia in both neural tube and mouse embryonic fibroblast cilia, even after blocking

113 retrograde ciliary traffic. We report that $A / 13 b^{V 358 A} / V 358 A$ mice were viable, fertile, and

114 transduced Shh signal normally. We found ARL3 and INPP5E did not localize to the

115 short cilia present in/on Arl13 $b^{V 358 A / V 358 A}$ cells. These data indicate that ARL13B's roles

116 within and outside cilia can be uncoupled; $A R L 13 B$ 's role in regulating cilia length is

117 from within cilia, whereas its control of Shh signaling appears to be from outside the

118 cilium. Thus, these data imply that the cilia defects seen in the complete absence of

119 ARL13B do not underlie the alterations in Shh transduction, which is unexpected given

120 the requirement of cilia for Shh signal transduction.

\section{Results}

$121 \quad$ ARL13B $^{\mathrm{V} 358 \mathrm{~A}}$ displays normal GEF activity

122 We previously showed that mouse $A R L 13 B^{V 358 A}$ protein retained normal intrinsic

123 and GAP-stimulated GTP hydrolysis activities by analyzing GST-ARL13B ${ }^{\text {V358A }}$ purified 
124 from human embryonic kidney (HEK) cells (Mariani et al. 2016). In order to test

$125 \mathrm{ARL}^{13 B^{\mathrm{V} 358 \mathrm{~A}}}$ GEF activity for ARL3, we used the same GST-ARL13B ${ }^{\mathrm{V} 38 \mathrm{~A}}$ protein

126 preparation and measured the rates of spontaneous or GEF-stimulated GDP

127 dissociation from ARL3 in the presence and absence of ARL13B or ARL13B ${ }^{V 358 A}$. ARL3

128 spontaneously releases pre-bound GDP quite slowly under the conditions in the assay,

129 though release is linear with time, and by extrapolation requires just under 30 min for

$13050 \%$ of pre-bound $\left[{ }^{3} \mathrm{H}\right] \mathrm{GDP}$ to dissociate (Figure 1). In marked contrast, addition of

131 ARL13B under the same conditions caused the release of $50 \%$ of the GDP within $\sim 10$

132 seconds and close to $100 \%$ in one minute. We detected no differences between the wild

133 type and mutant $A R L 13 B^{\mathrm{V} 358 \mathrm{~A}}$ proteins in this assay, consistent with this point mutation

134 having no effect on ARL13B GEF function (Figure 1). This result is consistent with GEF

135 activity being conserved within the protein's GTPase domain while the V358A mutation

136 is located in the C-terminal domain (Gotthardt et al. 2015). These data indicate that

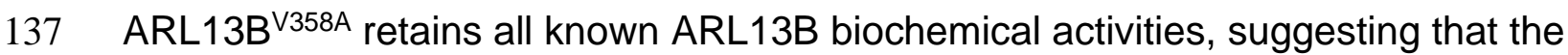

138 V358A mutation only disrupts ARL13B localization.

\section{CRISPR engineered Arl13b $\mathrm{V}^{\mathrm{V38A} / \mathrm{V} 358 \mathrm{~A}}$ mice express cilia-excluded ARL13B protein.}

To determine the consequences of $A R L 13 B^{V 358 A}$ expression in vivo, we used

142 CRISPR/Cas9 editing to change residue 358 from valine to alanine (Figure 2A). We

143 performed sequencing of the region that flanked exon 8, using primers outside the

144 region of the donor oligonucleotide. We confirmed the heterozygous $\mathrm{T}$ to $\mathrm{C}$ base pair

145 change for a valine to alanine change at residue 358 (Figure 2B). We backcrossed 
146 heterozygous F1 progeny to FVB/NJ for three generations before analysis to minimize

147 any off target confounds (see details in Methods).

148 To determine whether $A R L 13 B^{\mathrm{V} 358 \mathrm{~A}}$ was detectable in neural tube cilia, we

149 performed immunofluorescence using antibodies directed against ARL13B and the cilia

150 marker IFT88. At embryonic day (E)10.5, we saw IFT88 staining, indicating the

151 presence of cilia. In neural tube cilia of $A r / 13 b^{+/+}$and $A r / 13 b^{V 358 A /+}$ embryos, we

152 observed equivalent $A R L 13 B$ staining but could not see $A R L 13 B$ signal in neural tube

153 cilia of $A r l 13 b^{V 358 A / V 358 A}$ embryos (Figure 2C). We exposed the images longer, to

154 saturation, and while we observed low-level staining throughout the cell, we saw no

155 ciliary $A R L 13 B$ indicating the $A R L 13 B^{V 358 A}$ protein is undetectable in cilia in vivo (Figure

1562 - Figure supplement 1).

157 One possible explanation for the absence of ciliary ARL13B in the

$158 A r l 13 b^{V 358 A / V 358 A}$ embryos is that the ARL13B ${ }^{\mathrm{V} 358 \mathrm{~A}}$ protein is not expressed or is

159 unstable. To determine whether ARL13B protein expression was affected by the V358A

160 mutation, we performed Western blots on E10.5 whole embryo lysates (Figure 2D). We

161 found a $\sim 7 \%( \pm 20 \%)$ reduction of $A R L 13 B$ levels in Arl13bV358A+ embryos and a $\sim 37 \%$

$162( \pm 6 \%)$ decrease of ARL13B levels in Arl13bV358A/V358A embryos, compared to WT

163 (Figure 2E). This decrease may reflect a change in ARL13B ${ }^{\mathrm{V} 358 \mathrm{~A}}$ stability compared to

164 ciliary $A R L 13 B$ or could signify $A R L 13 B^{V 358 A}$ protein having a distinct half-life when

165 localizing to different cellular compartments. Regardless, these data indicate that

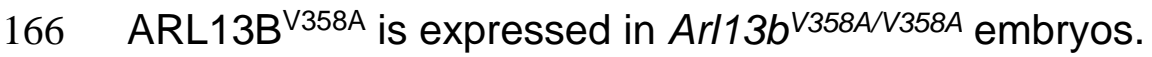


$A R L 13 B^{V 358 A}$ protein is undetectable in cilia in mouse embryonic fibroblasts.

To more closely investigate whether any $A R L 13 B^{\vee 358 A}$ protein could localize to

171 cilia, we generated immortalized mouse embryonic fibroblasts (MEFs). We performed

172 double labeling to first identify cilia using acetylated $\alpha$-tubulin or IFT88 antibodies and

173 subsequently determined whether $A R L 13 B$ is present in cilia. We used five distinct

174 antibodies against ARL13B: 4 antibodies against amino acids 208-427 of the mouse

175 ARL13B protein (1 mouse monoclonal (NeuroMab), 3 rabbit polyclonal antibodies

176 (Caspary et al. 2007)), as well as 1 antibody against the full-length human ARL13B

177 protein (rabbit polyclonal (Protein Tech)). By eye, we observed strong ciliary staining of

$178 \mathrm{ARL} 13 \mathrm{~B}$ with each of the antibodies in $\mathrm{Arl13} \mathrm{b}^{+/+}$and $\mathrm{Arl13} \mathrm{b}^{V 358 \mathrm{~A} /+}$ cells, but we were

179 unable to identify any evidence of ARL13B staining above background within cilia in

$180 A r 113 b^{V 358 A / V 358 A}$ cells with any of these five antibodies (Figure 3A). Taken together,

181 these data support our conclusion that $A R L 13 B^{V 358 A}$ is not detectable in cilia using the

182 currently available, validated ARL13B antibodies. While we observed no evidence of

183 detectable ciliary ARL13B in Arl13bV358A/V358A MEFs, it is possible that a small amount of

$184 \mathrm{ARL} 13 \mathrm{~B}^{\mathrm{V} 358 \mathrm{~A}}$ is constantly trafficking in and out of cilia, at steady-state levels that

185 remain below the limits of detection. To begin to address this possibility, we blocked

186 retrograde ciliary transport, reasoning that any ARL13B undergoing trafficking in and out

187 of cilia would accumulate. We treated cells with ciliobrevin-D, which blocks the

188 retrograde motor protein dynein (Firestone et al. 2012). As a positive control, we

189 examined IFT88 and Gli3, a ciliary protein and a Hh component, respectively; both are

190 known to accumulate at ciliary tips upon blocking of retrograde transport. We found

191 IFT88 and Gli3 enrichment at ciliary tips in $A r l 13 b^{+/+}, A r l 13 b^{V 358 A++}$ and $A r l 13 b^{V 358 A / V 358 A}$ 
192 cells upon ciliobrevin-D treatment relative to the respective DMSO-treated controls with

193 no difference in IFT88 or Gli3 staining among the 3 genotypes (Figure 3B and C). To

194 determine whether ARL13B accumulated in cilia of ciliobrevin-D-treated MEFs, we

195 examined cells co-stained for acetylated $\alpha$-tubulin and ARL13B. In Arl13b+/+ and

$196 A r l 13 b^{V 358 A+}$ cells, we saw that about $90 \%$ of acetylated $\alpha$-tubulin-positive cilia also

197 stained for ARL13B in DMSO-treated control or ciliobrevin-D treated MEFs (Figure 3D

198 and E). In Arl13b V358A/V358A MEFs, we saw no ciliary ARL13B staining in DMSO-treated

199 control or ciliobrevin-D-treated cells using 2 antibodies against distinct epitopes (Figure

200 3D and E). Thus, even when retrograde traffic out of cilia is disrupted, we were unable

201 to detect ARL13B protein in cilia in Arl13bV358A/V358A MEFs.

We re-examined these data and repeated our analyses using over-exposed

203 images. After defining the region of interest using the acetylated $\alpha$-tubulin staining, we

204 subsequently overexposed the ARL13B channel five-fold relative to the images in

205 Figure 3 and acquired measurements at the cilium and the cell body (Figure 3 - Figure

206 supplement 1). As a control, we used Arl13 $b^{h n n / h n n}$ MEFs, which are devoid of any

207 ARL13B, and obtained a ratio of 1.0, with or without ciliobrevin-D treatment. We found

208 the same ratio when we analyzed $A r l 13 b^{V 358 A / V 358 A}$ MEFs consistent with ARL13B being

209 absent from the cilia. We observed a few instances of ARL13B appearing to co-localize

210 with acetylated $\alpha$-tubulin, but these were rare $(<5 \%, 2 / 49)$ and occurred in both

$211 A r l 13 b^{V 358 A / V 358 A}$ and $A r l 13 b^{h n n / h n n}$ (null) cells indicating this is the background staining of

212 the primary antibody. We extended our analysis of overexposed images in

$213 A r l 13 b^{V 358 A / V 358 A}$ and $A r l 13 b^{h n n / h n n}$ neural tube sections four-fold relative to the images in

214 Figure 2; we identified no overlap of overexposed ARL13B with cilia marker IFT88 
215 (Figure 2 - Figure supplement 1). While it is formally possible that an extremely small

216 amount of $A R L 13 B^{V 358 A}$ remains in cilia, we are not able to find evidence of it; thus, we

217 designate $A R L 13 B^{\mathrm{V} 358 \mathrm{~A}}$ protein as cilia-excluded ARL13B.

218 We did not observe any obvious cellular ARL13B signal in the cells expressing

219 cilia-excluded ARL13B so we investigated whether we could detect cellular ARL13B in

220 cells lacking cilia, IFT172wim MEFs. As controls we used wildtype, Arl13bhnn (lacking

221 ARL13B), and IFT172wim Arl13bhnn (lacking ARL13B and cilia) MEFs. We only detected

222 ARL13B staining in IFT172wim cells upon overexposure and found it was modestly

223 detectable above the background level we observed in Arl13b $b^{\text {hnn }}$ or IFT172wim Arl13b

224 cells (Figure 3 - Figure supplement 2). Thus, cellular ARL13B is expressed at an

225 extremely low level.

226

\section{Arl13b $b^{V 358 A / V 358 A}$ mice are viable and fertile.}

In order to determine the phenotypic consequence of the Arl13bV358A allele, we

228 intercrossed $A r l 13 b^{V 358 A /+}$ mice. We observed progeny in Mendelian proportions with an

229 average of 7.3 pups per litter, consistent with the reported FVB/NJ litter size of 7-9

230 (Murray et al. 2010) (Table 1). To test whether homozygous mice breed normally, we

231 crossed Arl13bV358A/V358A males to heterozygous or homozygous females. We found the

$232 A r l 13 b^{V 358 A}$ allele segregated in Mendelian proportions and the litter sizes were normal

233 indicating that $A r l 13 b^{V 358 A}$ does not impact viability, fertility or fecundity. 


\section{$A R L 13 B^{V 358 A}$ permits normal embryonic development and Shh signaling.}

Loss of $A r l 13 b$ leads to morphologically abnormal embryos, lethality and neural

239 patterning defects (Caspary et al. 2007). As $A R L 13 B^{V 358 A}$ overcame the embryonic

240 lethality, we examined overall embryo morphology at E9.5, E10.5 and E12.5. We found

241 the overall morphology of $A r 113 b^{V 358 A / V 358 A}$ embryos resembled those of $A r l 13 b^{+/+}$and

$242 A r l 13 b^{V 358 A /+}$ embryos indicating that $A R L 13 B^{V 358 A}$ did not lead to gross morphological

243 defects. (Figure 4A-I).

At E9.5, Shh is normally expressed in the notochord as well as the floor plate of

245 the ventral neural tube. Moving dorsally, the adjacent domains express Nkx2.2 and

246 subsequently Olig2. In the $A r l 13 b^{h n n / h n n}$ (null) neural tube, the Shh-positive columnar

247 cells of the floor plate are absent resulting in both ventral and dorsal expansion of

248 intermediate Shh-dependent cell fates such as Olig2 (Caspary et al. 2007). To

249 determine whether $A R L 13 B^{\mathrm{V} 358 \mathrm{~A}}$ disrupts Shh signaling, we examined neural tube

250 patterning in $A r l 13 b^{+/+}, A r l 13 b^{V 358 A /+}$, and $A r l 13 b^{V 358 A / V 358 A}$ embryos at E9.5, E10.5, and

251 E12.5. At E9.5 we observed no differences in Shh, Nkx2.2 or Olig2 among Arl13b+/,

$252 A r l 13 b^{V 358 A /+}$, and Arl13 $b^{V 358 A / V 358 A}$ embryos (Figure 4A-C). Cell fates in the neural tube

253 are specified by both the concentration and duration of Shh signaling so we examined

254 neural patterning at subsequent stages (Dessaud et al. 2007). By E10.5, some Olig2

255 precursors have differentiated to HB9+ motor neurons and all Shh-responsive cells

256 express Nkx6.1. We found that Olig2, HB9 and Nkx6.1 positive cells are normally

257 distributed in all 3 genotypes at E10.5 and E12.5 (Figure 4D-I). These data indicate that

258 ARL13B ${ }^{\mathrm{V} 358 \mathrm{~A}}$ mediates normal Shh signaling. 
ARL13B regulates ciliary enrichment of Shh components from outside cilia.

In Arl13b $b^{h n n / h n n}$ cells, Smo is enriched in cilia in a Shh-independent manner,

262 which may be due to defective trafficking of Smo, as many $A R L$ family members

263 regulate protein trafficking (Lim et al. 2011; Larkins et al. 2011). To assess Smo

264 enrichment in Arl13b ${ }^{V 358 A / V 358 A}$ embryos, we stained for the cilia marker acetylated $\alpha$ -

265 tubulin and Smo in E10.5 embryos. Smo appeared enriched normally in ventral floor

266 plate cilia and the dorsal boundary of Smo ciliary enrichment in ventral neural

267 progenitors was identical in $A r l 13 b^{+/+}, A r l 13 b^{V 358 A /+}$, and $A r l 13 b^{V 358 A / V 358 A}$ samples

268 indicating ARL13B ${ }^{\mathrm{V} 358 \mathrm{~A}}$ mediates normal ciliary Smo enrichment (Figure 5A).

269 To examine Smo traffic in response to Shh stimulation, we treated MEFs with

$270 \quad 0.5 \%$ FBS or Shh-conditioned media for 24 hours and stained for Smo. As expected in

271 control Arl13b $b^{h n n / h n n}$ cells, we saw ciliary Smo in unstimulated MEFs which increased

272 upon stimulation with Shh-conditioned media (Larkins et al. 2011) (Figure 5B). In

$273 A r l 13 b^{+/+}, A r l 13 b^{V 358 A /+}$, and $A r l 13 b^{V 358 A / V 358 A}$ MEF cilia, we saw ciliary enrichment of

274 Smo upon Shh stimulation over their respective unstimulated controls (Figure 5B, left).

275 We found no difference in Smo enrichment among these cell lines (Figure 5B, right).

276 Thus, despite ARL13B being critical for Shh-dependent Smo ciliary enrichment,

277 ARL13B ${ }^{V 358 A}$ regulates Smo localization normally, arguing this function of ARL13B can

278 occur when the protein is not in cilia.

279 In addition to aberrations in Smo trafficking, loss of Arl13b leads to changes in

280 the cilia localization of other Shh components in MEFs (Larkins et al. 2011). To

281 determine whether these components are disrupted by $A R L 13 B^{\vee 358 A}$, we examined Gli2,

282 Gli3, Sufu and Ptch1 in MEFs. We observed no differences in distribution of Gli2 or 
283 Ptch1 among any of the examined genotypes (Figure 5C, F). In contrast, as we

284 previously reported, we observed more Gli3 at the ciliary tip of $A r l 13 b^{h n n / h n n}$ cells and

285 increased Sufu in Arl13bhnn/hnn cilia compared to wild type controls (Larkins et al.

286 2011)(Figure 5D, E). Thus, Shh components are normally localized in Arl13bV358A/V358A

287 MEFs consistent with the normal Shh signal transduction observed in Arl13bV358A/V358A

288 embryos (Figure 4).

ARL13B regulates ciliary enrichment of ARL3 and INPP5E from within cilia.

We next examined the role of $A R L 13 B^{\mathrm{V} 358 \mathrm{~A}}$ in the localization of other ciliary

292 proteins. ARL13B is the GEF for ARL3, and we showed that ARL13B ${ }^{\vee 358 A}$ GEF activity

293 for ARL3 is retained (Figure 1). ARL13B is also essential for cilia localization of

294 INPP5E, as the proteins are in a common complex (Humbert et al. 2012). To determine

295 whether the ciliary localization of either ARL3 or INPP5E was affected by ARL13B ${ }^{\mathrm{V} 358 \mathrm{~A}}$,

296 we performed immunofluorescence on MEFs. Ciliary ARL3 staining appeared the same

297 in $A r l 13 b^{+/+}$and $A r l 13 b^{V 358 A /+}$ MEFs, however ARL3 was not detectable in

$298 A r l 13 b^{V 358 A / V 358 A}$ or Arl13 $b^{h n n / h n n}$ cilia (Figure 5G). INPP5E was normally detectable in

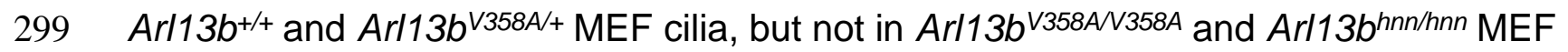

300 cilia (Figure $\mathbf{5 H}$ ). These results indicate that ARL13B is required in cilia for the proper

301 localization of ARL3 and INPP5E to the cilium.

302

303 Ciliary ARL13B is required for normal cell ciliation and ciliary length

Loss of Arl13b leads to defects in the percentage of ciliated MEFs and in cilia

305 length (Caspary et al. 2007; Larkins et al. 2011). To test whether ARL13B ${ }^{V 358 A}$ impacted 
306 cell ciliation, we examined immortalized MEFs and counted the number of ciliated cells

30724 hours after induction of ciliation by growth in low serum (0.5\% FBS). We found $73 \%$

$308( \pm 11 \%)$ of $A r l 13 b^{+/+}$and $75 \%,( \pm 9.1 \%)$ of $A r l 13 b^{V 358 A /+}$ MEFs are ciliated, consistent with

309 published results. In contrast, we found $45 \%( \pm 8.7 \%)$ of $A r / 13 b^{V 358 A / V 358 A}$ cells and $53 \%$

$310( \pm 6.4 \%)$ of $A r l 13 b^{h n n / h n n}$ cells had cilia (Figure $\left.6 \mathrm{~A}\right)$. Thus, Arl13b ${ }^{V 358 A / V 358 A}$ cells exhibit a

311 similar deficit in percentage of ciliated MEFs as complete loss of ARL13B function.

$312 A r l 13 b^{h n n / h n n}$ cilia are about half as long as wild type in both embryos and MEFs

313 (Caspary et al. 2007; Larkins et al. 2011). To determine whether cilia length was

314 affected by $A R L 13 B^{\mathrm{V} 358 \mathrm{~A}}$, we stained MEFs with acetylated $\alpha$-tubulin and measured the

315 length of the axoneme. We found the average cilia length in $\mathrm{Arl} 13 \mathrm{~b}^{+/+}$and $\mathrm{Arl} 13 \mathrm{~b}^{\mathrm{V} 358 \mathrm{~A} /+}$

316 MEFs was similar, $2.7 \pm 0.8 \mu \mathrm{m}$ and $2.6 \pm 0.9 \mu \mathrm{m}$, respectively. However, we found

317 Arl13bV358A/V358A MEF cilia were shorter, $1.9 \pm 0.7 \mu \mathrm{m}$, similar to Arl13b

318 which were $2.15 \pm 0.8 \mu \mathrm{m}$ (Figure 6B). These results indicate that $A R L 13 B^{V 358 A}$

319 phenocopies complete loss of ARL13B for ciliation and cilia length, indicating these

320 ARL13B functions require $A R L 13 B$ in cilia. Furthermore, these data show that $A R L 13 B$

321 function within cilia is distinct from ARL13B function outside of cilia in a subset of

322 activities, and that the cilia defects and Shh defects in the complete absence of ARL13B

323 can be uncoupled.

\section{Discussion}

Here we show that ARL13B's role(s) in cell ciliation and cilia length, along with

325 the ciliary enrichment of a subset of proteins, can be uncoupled from ARL13B's function

326 in regulating Shh signal transduction (Figure 7). Furthermore, we show this functional 
327 distinction correlates with ARL13B spatial localization to the cilium. By generating a

328 mouse expressing a cilia-excluded variant of ARL13B from the endogenous locus, we

329 showed ARL13B ${ }^{\mathrm{V} 358 \mathrm{~A}}$ protein is not detectable in cilia of embryonic neural tube or

330 MEFs, even upon retrograde ciliary dynein traffic blockade. Furthermore, we detected

$33130 \%$ less ARL13B protein overall in Arl13bV358A/V358A embryos compared to control

332 embryos. While this reduction is statistically significant, it is unclear whether it is

333 biologically significant given that $A r l 13 b^{h n n / h n n}$ null mutations are recessive and no

$334 A r l 13 b^{h n n /+}$ heterozygous phenotype is reported (Caspary et al. 2007; Larkins et al.

335 2011).

336 In contrast to the E13.5 lethality of $A r l 13 b^{h n n / h n n}$ embryos, we found

337 Arl13b $b^{V 358 / V 358 A}$ mice were viable and fertile with correct patterning of the neural tube,

338 indicating normal Shh signal transduction. These results are consistent with our data

339 showing that $A R L 13 B^{V 358 A}$ protein retains all known biochemical function including GEF

340 activity (Mariani et al. 2016; Ivanova et al. 2017). However, we observed several

341 Arl13 $b^{h n n / h n n}$ phenotypes in Arl13b $b^{V 358 A V 358 A}$ cells, including loss of ARL3 and INPP5E

342 ciliary enrichment, along with low percentage of ciliated cells and shorter average cilia

343 length. Taken together, our data show that despite the normal high ciliary enrichment of

344 wild type ARL13B and the requirement of cilia for Shh signaling, cilia-excluded

$345 \mathrm{ARL} 13 \mathrm{~B}^{\mathrm{V} 358 \mathrm{~A}}$ is sufficient for Shh signal transduction.

346 We regard $A R L 13 B^{V 358 A}$ as cilia-excluded based on several lines of evidence.

347 We did not detect ciliary ARL13B ${ }^{\mathrm{V} 358 \mathrm{~A}}$ in vivo or in vitro using any of five validated

348 ARL13B antibodies. These antibodies are against two antigens, the full-length protein or

349 residues 208-427, and were independently generated so are likely to recognize a 
350 number of epitopes. Given that 4 of 5 antibodies are polyclonal and $A R L 13 B$ V358A

351 displays normal GTP binding, intrinsic and GAP-stimulated GTP hydrolysis, and ARL3

352 GEF activity, it is likely that the $A R L 13 B^{V 358 A}$ protein retains the wild type structure

353 enabling antibody recognition. Indeed, we observed little or no loss in sensitivity in

354 detecting protein in the immunoblot assays. Furthermore, we could not forcibly enrich

355 ciliary $A R L 13 B^{V 358 A}$ through retrograde transport blockade with ciliobrevin-D nor could

356 we detect any ciliary enrichment of $A R L 13 B^{\mathrm{V} 358 \mathrm{~A}}$ upon overexposure of the relevant

357 fluorescent channel. Alternative ways of trafficking proteins out of cilia include BBSome-

358 dependent or diffusion-dependent mechanisms raising the possibility that $A R L 13 B$ is not

359 trafficked via dynein-independent mechanisms. The fact that we observed ciliary

360 phenotypes, namely short cilia and abnormal ciliary ARL3 and INPP5E localization in

361 ARL13B ${ }^{\mathrm{V} 358 \mathrm{~A}}$ cells, argue that ARL13B normally performs these functions from within

362 cilia (Caspary et al. 2007; Larkins et al. 2011; Zhang et al. 2016; Humbert et al. 2012;

363 Nozaki et al. 2017). While we cannot exclude the possibility that sub-detectable levels of

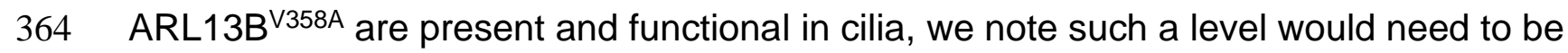

365 sufficient for Shh signaling yet insufficient for ARL3 or INPP5E ciliary localization along

366 with proper regulation of cilia length.

367 Our data support ARL13B regulating different biological processes from its

368 distinct subcellular localizations. ARL13B ${ }^{\mathrm{V} 358 \mathrm{~A}}$ disrupts cilia localization of INPP5E and

369 ARL3, but not Shh components. It is surprising that $A R L 13 B^{\vee 358 A}$ is sufficient to regulate

370 Shh signaling because cilia are required for Shh signal transduction and because

371 ARL13B is highly enriched in cilia (Caspary et al. 2007; Huangfu et al. 2003). These

372 observations suggested that the ciliary defects observed in Arl13bhnn/hnn mutants caused 
373 the Shh defects. However, our data with $A R L 13 B^{V 358 A}$ indicate that $A R L 13 B$ regulates

374 cilia length and Shh signaling through distinct localization and effectors. Thus, the cilia

375 defects in Arl13 $b^{h n n / h n n}$ mutants do not underlie Shh misregulation.

376 Based on the normal cilia trafficking of Shh components in Arl13bV358A/V358A

377 mutants and the abnormal cilia trafficking of Shh components in the complete absence

378 of ARL13B (Larkins et al. 2011), ARL13B likely regulates Shh signaling from the cell

379 body by controlling Shh component traffic to and/or from the primary cilium. Both Smo

380 and ARL13B traffic is linked to endosomes providing one possible non-ciliary organelle

381 (Barral et al. 2012; Wang et al. 2009; Milenkovic et al. 2009). Arl13b

382 constitutive Smo ciliary enrichment along with little enrichment of Gli proteins at the

383 ciliary tip (Larkins et al. 2011). Our data do not distinguish between ARL13B playing

384 direct roles in traffic of multiple Shh components or whether the normal Smo ciliary

385 enrichment with $A R L 13 B^{\mathrm{V} 358 \mathrm{~A}}$ subsequently causes normal cilia traffic of downstream

386 components. ARL13B regulates a step downstream of activated Smo that controls

387 transcription factor Gli activation, but not repression (Caspary et al. 2007; Bay et al.

388 2018). We argue from our results that this step is also intact in the presence of

389 ARL13B ${ }^{\mathrm{V} 358 \mathrm{~A}}$.

$390 \quad$ The fact that $A R L 13 B^{V 358 A}$ can mediate normal ciliary Smo enrichment is

391 especially interesting given that ARL3 and INPP5E localization to cilia is compromised

392 by this mutation. This suggests that ARL13B controls cilia enrichment via multiple

393 localizations and effectors. This is consistent with our understanding of ARF family

394 members, as they are known to perform multiple tasks from different sites within a cell

395 (Sztul et al. 2019). We speculate that ARL3 residence in cilia may require that ARL3 be 
396 in (or at least cycle through) its activated, GTP-bound conformation as ARL13B ${ }^{\text {V358A }}$

397 retains its ARL3 GEF activity, but not its cilia localization. ARL13B is in a common

398 protein complex with INPP5E so absence of ARL13B from cilia may disrupt formation or

399 maintenance of the complex there (Humbert et al. 2012; Nozaki et al. 2017). INPP5E

400 regulates Shh signaling through regulation of the phosphoinositol composition of the

401 ciliary membrane. INPP5E loss results in increased ciliary $\mathrm{PIP}_{2}$ and enrichment of Shh

402 repressors in cilia thus resulting in lowered Shh response (Garcia-Gonzalo et al. 2015;

403 Chavez et al. 2015; Dyson et al. 2017). It is not clear why the absence of ciliary INPP5E

404 in ARL13B ${ }^{\mathrm{V} 358 \mathrm{~A}}$ cells does not lead to aberrant Shh signal transduction.

In Arl13 $b^{h n n / h n n}$ embryos and MEFs, cilia are shorter than normal and have a

406 microtubule defect where the B-tubule of the microtubule outer doublet is open

407 (Caspary et al. 2007; Larkins et al. 2011). Consistent with this, we observed shorter cilia

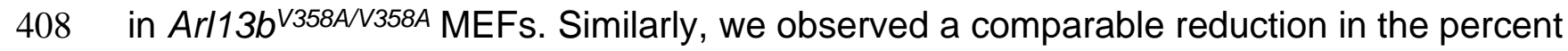

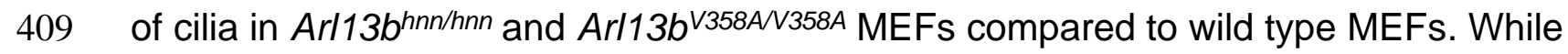

410 loss of ARL13B results in short cilia, increased expression of ARL13B promotes cilia

411 elongation so it is not yet clear what ARL13B's role is in controlling cilia length (Lu et al.

412 2015; Hori et al. 2008; Caspary et al. 2007; Larkins et al. 2011). Additionally, it is

413 unclear whether the mechanism from within cilia through which $A R L 13 B$ controls length

414 or percent of ciliated cells is the same, or distinct from, the mechanism through which

415 ARL13B regulates ARL3 or INPP5E residence in cilia.

416 Perhaps the most intriguing implication of our data pertains to understanding the

417 evolution of cilia and Hh signaling. ARL13 functions in cilia formation and maintenance

418 in Chlamydomonas and $C$. elegans, neither of which have Hh signaling, consistent with 
419 the ancient role of ARL13 controlling ciliation and cilia length (Cevik et al. 2010; Cevik et

420 al. 2013; Stolc et al. 2005; Miertzschke et al. 2014). Our data support ARL13B retaining

421 ARL13's ancient role in ciliogenesis. However, our data show that ARL13B does not

422 work from within the cilium to regulate Shh component ciliary traffic or Shh signal

423 transduction. As an ARL protein involved in membrane traffic, we speculate that

424 ARL13B may have linked Shh component trafficking to the primary cilium, albeit from

425 outside the cilium. That the ARL13 duplication could relate to the mechanism linking

426 primary cilia and Hh signaling within the deuterostome lineage is a possibility worth

427 exploring.

\begin{tabular}{|c|c|c|c|c|}
\hline \multicolumn{5}{|c|}{ Key Resources Table } \\
\hline $\begin{array}{l}\text { Reagent type } \\
\text { (species) or } \\
\text { resource }\end{array}$ & Designation & $\begin{array}{l}\text { Source or } \\
\text { reference }\end{array}$ & Identifiers & $\begin{array}{l}\text { Additional } \\
\text { information }\end{array}$ \\
\hline $\begin{array}{l}\text { gene (M. } \\
\text { Musculus) }\end{array}$ & $A r l 13 b$ & & $\begin{array}{l}\text { MGI Cat\# } \\
6115585, \\
\text { RRID:MGI:611558 } \\
5\end{array}$ & \\
\hline $\begin{array}{l}\text { Genetic reagent } \\
\text { (M. Musculus) }\end{array}$ & hennin & PMID:17488627 & $\begin{array}{l}\text { MGI Cat\# } \\
\text { 3580673, } \\
\text { RRID:MGI:358067 } \\
3\end{array}$ & $\begin{array}{l}\text { Arl13b null } \\
\text { allele }\end{array}$ \\
\hline $\begin{array}{l}\text { Genetic reagent } \\
\text { (M. Musculus) }\end{array}$ & $\begin{array}{l}\text { em1Tc } \\
(\text { V358A) }\end{array}$ & This paper & $\begin{array}{l}\text { MGI: } \\
6256969\end{array}$ & $\begin{array}{l}\text { New } \\
\text { CRISPR } \\
\text { Point } \\
\text { mutant }\end{array}$ \\
\hline $\begin{array}{l}\text { Genetic reagent } \\
\text { (M. Musculus) }\end{array}$ & $\mathrm{FBV} / \mathrm{NJ}$ & $\begin{array}{l}\text { Jackson } \\
\text { Laboratory }\end{array}$ & $\begin{array}{l}\text { Stock \#001800 } \\
\text { MGl:2163709 }\end{array}$ & \\
\hline $\begin{array}{l}\text { cell lines (M. } \\
\text { Musculus) }\end{array}$ & $\begin{array}{l}\text { Fibroblast } \\
\text { (normal, } \\
\text { embryonic) }\end{array}$ & This paper & & $\begin{array}{l}\text { Maintained } \\
\text { in Caspary } \\
\text { lab }\end{array}$ \\
\hline
\end{tabular}




\begin{tabular}{|c|c|c|c|c|}
\hline Antibody & $\begin{array}{l}\text { Anti-Shh } \\
\text { (Mouse } \\
\text { Monoclonal) }\end{array}$ & $\begin{array}{l}\text { Developmental } \\
\text { Studies } \\
\text { Hybridoma Bank }\end{array}$ & $\begin{array}{l}\text { DSHB Cat\# 5E1, } \\
\text { RRID:AB_528466 }\end{array}$ & $1: 5$ \\
\hline Antibody & $\begin{array}{l}\text { Anti-Nkx2.2 } \\
\text { (Mouse } \\
\text { Monoclonal) }\end{array}$ & $\begin{array}{l}\text { Developmental } \\
\text { Studies } \\
\text { Hybridoma Bank }\end{array}$ & $\begin{array}{l}\text { DSHB Cat\# } \\
\text { 74.5A5, } \\
\text { RRID:AB_531794 }\end{array}$ & $1: 5$ \\
\hline Antibody & $\begin{array}{l}\text { Anti-Hb9 } \\
\text { (Mouse } \\
\text { Monoclonal) }\end{array}$ & $\begin{array}{l}\text { Developmental } \\
\text { Studies } \\
\text { Hybridoma Bank }\end{array}$ & $\begin{array}{l}\text { DSHB Cat\# } \\
\text { 81.5C10, } \\
\text { RRID:AB_214520 } \\
9\end{array}$ & $1: 5$ \\
\hline Antibody & $\begin{array}{l}\text { Anti-Nkx6.1 } \\
\text { (Mouse } \\
\text { Monoclonal) }\end{array}$ & $\begin{array}{l}\text { Developmental } \\
\text { Studies } \\
\text { Hybridoma Bank }\end{array}$ & $\begin{array}{l}\text { DSHB Cat\# } \\
\text { F55A10, } \\
\text { RRID:AB_532378 }\end{array}$ & $1: 50$ \\
\hline Antibody & $\begin{array}{l}\text { Anti- } \\
\text { acetylated } \\
\text { a-tubulin } \\
\text { (Mouse } \\
\text { Monoclonal) }\end{array}$ & Millipore Sigma & $\begin{array}{l}\text { Sigma-Aldrich } \\
\text { Cat\# T6793, } \\
\text { RRID:AB_477585 }\end{array}$ & $1: 2500$ \\
\hline Antibody & $\begin{array}{l}\text { Anti-Olig2 } \\
\text { (Rabbit } \\
\text { Polyclonal) }\end{array}$ & Millipore Sigma & $\begin{array}{l}\text { Millipore Cat\# } \\
\text { AB9610, } \\
\text { RRID:AB_570666 }\end{array}$ & $1: 300$ \\
\hline Antibody & $\begin{array}{l}\text { Anti-Arl13b } \\
\text { (Mouse } \\
\text { Monoclonal) }\end{array}$ & NeuroMab & $\begin{array}{l}\text { UC Davis/NIH } \\
\text { NeuroMab Facility } \\
\text { Cat\# 73-287, } \\
\text { RRID:AB_110000 } \\
53\end{array}$ & $1: 1000$ \\
\hline Antibody & $\begin{array}{l}\text { Anti-Arl13b } \\
\text { (Rabbit } \\
\text { Polyclonal }\end{array}$ & Protein Tech & $\begin{array}{l}\text { Proteintech Cat\# } \\
\text { 17711-1-AP, } \\
\text { RRID:AB_206086 } \\
7\end{array}$ & $1: 1000$ \\
\hline Antibody & $\begin{array}{l}\text { Anti-Arl13b } \\
\text { (Rabbit } \\
\text { Polyclonal }\end{array}$ & PMID:17488627 & 503 & $1: 1000$ \\
\hline Antibody & $\begin{array}{l}\text { Anti-Arl13b } \\
\text { (Rabbit } \\
\text { Polyclonal }\end{array}$ & PMID:17488627 & 504 & $1: 1000$ \\
\hline Antibody & $\begin{array}{l}\text { Anti-Arl13b } \\
\text { (Rabbit } \\
\text { Polyclonal }\end{array}$ & PMID:17488627 & 505 & $1: 1000$ \\
\hline
\end{tabular}




\begin{tabular}{|c|c|c|c|c|}
\hline Antibody & $\begin{array}{l}\text { Anti-Smo } \\
\text { (Rabbit } \\
\text { Polyclonal) }\end{array}$ & K. Anderson & & $1: 1000$ \\
\hline Antibody & $\begin{array}{l}\text { Anti-IFT88 } \\
\text { (Rabbit } \\
\text { Polyclonal) }\end{array}$ & B. Yoder & & $1: 1000$ \\
\hline Antibody & $\begin{array}{l}\text { Anti-Arl3 } \\
\text { (Rabbit } \\
\text { Polyclonal) }\end{array}$ & PMID:8034651 & & $1: 1000$ \\
\hline Antibody & $\begin{array}{l}\text { Anti-Inpp5e } \\
\text { (Rabbit } \\
\text { Polyclonal) }\end{array}$ & Protein Tech & $\begin{array}{l}\text { Proteintech Cat\# } \\
\text { 17797-1-AP, } \\
\text { RRID:AB_216712 } \\
0\end{array}$ & $1: 150$ \\
\hline Antibody & $\begin{array}{l}\text { Anti-Gli2 } \\
\text { (Guinea Pig } \\
\text { Polyclonal) }\end{array}$ & $\begin{array}{l}\text { J. } \\
\text { Eggenschwiler }\end{array}$ & & $1: 200$ \\
\hline Antibody & $\begin{array}{l}\text { Anti-Gli3 } \\
\text { (Goat } \\
\text { Polyclonal) }\end{array}$ & R\&D & $\begin{array}{l}R \text { and D Systems } \\
\text { Cat\# AF3690, } \\
\text { RRID:AB_223249 } \\
9\end{array}$ & $1: 200$ \\
\hline Antibody & $\begin{array}{l}\text { Anti-Ptch1 } \\
\text { (Rabbit } \\
\text { Polyclonal) }\end{array}$ & R. Rohatgi & & $1: 150$ \\
\hline Antibody & $\begin{array}{l}\text { Anti-Sufu } \\
\text { (Goat } \\
\text { Polyclonal) }\end{array}$ & Santa Cruz & $\begin{array}{l}\text { Santa Cruz } \\
\text { Biotechnology } \\
\text { Cat\# sc-10933, } \\
\text { RRID:AB_671172 }\end{array}$ & $1: 100$ \\
\hline Antibody & $\begin{array}{l}\text { Alexa Fluor } \\
\text { goat anti- } \\
\text { mouse } \\
\text { lgG2a } 488\end{array}$ & ThermoFisher & $\begin{array}{l}\text { Thermo Fisher } \\
\text { Scientific Cat\# A- } \\
21131 \text {, } \\
\text { RRID:AB_253577 } \\
1\end{array}$ & $1: 300$ \\
\hline Antibody & $\begin{array}{l}\text { Alexa Fluor } \\
\text { goat anti- } \\
\text { mouse IgG1 } \\
488\end{array}$ & ThermoFisher & $\begin{array}{l}\text { Thermo Fisher } \\
\text { Scientific Cat\# A- } \\
21121 \text {, } \\
\text { RRID:AB_253576 } \\
4\end{array}$ & $1: 300$ \\
\hline Antibody & $\begin{array}{l}\text { Alexa Fluor } \\
\text { goat anti- } \\
\text { mouse Ig } 488\end{array}$ & ThermoFisher & $\begin{array}{l}\text { Molecular Probes } \\
\text { Cat\# A-11029, } \\
\text { RRID:AB_138404 }\end{array}$ & $1: 300$ \\
\hline
\end{tabular}




\begin{tabular}{|c|c|c|c|c|}
\hline Antibody & $\begin{array}{l}\text { Alexa Fluor } \\
\text { goat anti- } \\
\text { mouse IgG } \\
568\end{array}$ & ThermoFisher & $\begin{array}{l}\text { Thermo Fisher } \\
\text { Scientific Cat\# A- } \\
11031 \text {, } \\
\text { RRID:AB_144696 }\end{array}$ & $1: 300$ \\
\hline Antibody & $\begin{array}{l}\text { Alexa Fluor } \\
\text { donkey anti- } \\
\text { rabbit lgG } \\
488\end{array}$ & ThermoFisher & $\begin{array}{l}\text { Thermo Fisher } \\
\text { Scientific Cat\# A- } \\
21206 \text {, } \\
\text { RRID:AB_253579 } \\
2\end{array}$ & $1: 300$ \\
\hline Antibody & $\begin{array}{l}\text { Alexa Fluor } \\
\text { donkey anti- } \\
\text { rabbit lgG } \\
555\end{array}$ & ThermoFisher & $\begin{array}{l}\text { Thermo Fisher } \\
\text { Scientific Cat\# A- } \\
\text { 31572, } \\
\text { RRID:AB_162543 }\end{array}$ & $1: 300$ \\
\hline Antibody & $\begin{array}{l}\text { Alexa Fluor } \\
\text { goat anti- } \\
\text { rabbit IgG } \\
568\end{array}$ & ThermoFisher & $\begin{array}{l}\text { Thermo Fisher } \\
\text { Scientific Cat\# A- } \\
\text { 11011, } \\
\text { RRID:AB_143157 }\end{array}$ & $1: 300$ \\
\hline Antibody & $\begin{array}{l}\text { Alexa Fluor } \\
\text { goat anti- } \\
\text { mouse } \\
\text { lgG2b } 568\end{array}$ & ThermoFisher & $\begin{array}{l}\text { Thermo Fisher } \\
\text { Scientific Cat\# A- } \\
21147 \text {, } \\
\text { RRID:AB_253578 } \\
3\end{array}$ & $1: 300$ \\
\hline Antibody & $\begin{array}{l}\text { Hoechst } \\
\text { nuclear stain }\end{array}$ & Millipore Sigma & 94403 & $1: 3000$ \\
\hline $\begin{array}{l}\text { sequence- } \\
\text { based reagent }\end{array}$ & $\begin{array}{l}\text { CRISPR } \\
\text { gRNA }\end{array}$ & $\begin{array}{l}\text { Millpore Sigma, } \\
\text { this paper }\end{array}$ & & $\begin{array}{l}\text { CCAGTCA } \\
\text { ATACAGA } \\
\text { CGAGTCT } \\
\text { A }\end{array}$ \\
\hline $\begin{array}{l}\text { sequence- } \\
\text { based reagent }\end{array}$ & $\begin{array}{l}\text { CRISPR } \\
\text { donor oligo }\end{array}$ & $\begin{array}{l}\text { Millpore Sigma, } \\
\text { this paper }\end{array}$ & & $\begin{array}{l}\text { CCTATAT } \\
\text { TCTTCTA } \\
\text { GAAAACA } \\
\text { GTAAGAA } \\
\text { GAAAACC } \\
\text { AAGAAAC } \\
\text { TACGAAT } \\
\text { GAAAAGG } \\
\text { AGTCATC } \\
\text { GGGCAG } \\
\text { AACCAGT } \\
\text { GAATACA } \\
\text { GACGAGT } \\
\text { CTACTCC } \\
\text { AAAGAGT } \\
\text { CCCACGC }\end{array}$ \\
\hline
\end{tabular}




\begin{tabular}{|c|c|c|c|c|}
\hline & & & & $\begin{array}{l}\text { CTCCCCA } \\
\text { AC }\end{array}$ \\
\hline $\begin{array}{l}\text { sequence- } \\
\text { based reagent }\end{array}$ & F-231-Cac8I & This Paper & & $\begin{array}{l}\text { PCR } \\
\text { Primer AA } \\
\text { GAATGAA } \\
\text { AAGGAGT } \\
\text { CAGCG }\end{array}$ \\
\hline $\begin{array}{l}\text { sequence- } \\
\text { based reagent }\end{array}$ & REV-1 & This Paper & & $\begin{array}{l}\text { PCR } \\
\text { Primer } \\
\text { TGAACCG } \\
\text { CTAATGG } \\
\text { GAAACT }\end{array}$ \\
\hline $\begin{array}{l}\text { peptide, } \\
\text { recombinant } \\
\text { protein }\end{array}$ & $\begin{array}{l}\text { Arl13bWT- } \\
\text { GST }\end{array}$ & This Paper & & $\begin{array}{l}\text { Purified } \\
\text { from cells }\end{array}$ \\
\hline $\begin{array}{l}\text { peptide, } \\
\text { recombinant } \\
\text { protein }\end{array}$ & $\begin{array}{l}\text { Arl13bV358A_ } \\
\text { GST }\end{array}$ & This Paper & & $\begin{array}{l}\text { Purified } \\
\text { from cells }\end{array}$ \\
\hline $\begin{array}{l}\text { peptide, } \\
\text { recombinant } \\
\text { protein }\end{array}$ & $\begin{array}{l}\text { Arl3 } \\
\text { (human) }\end{array}$ & PMID:11303027 & & $\begin{array}{l}\text { Purified } \\
\text { from cells }\end{array}$ \\
\hline $\begin{array}{l}\text { peptide, } \\
\text { recombinant } \\
\text { protein }\end{array}$ & Cas9 & Millipore Sigma & C120010 & $50 \mu g$ \\
\hline $\begin{array}{l}\text { peptide, } \\
\text { recombinant } \\
\text { protein }\end{array}$ & Cac8I & $\begin{array}{l}\text { New England } \\
\text { Biolabs }\end{array}$ & R0579L & $\begin{array}{l}\text { Restriction } \\
\text { enzyme }\end{array}$ \\
\hline $\begin{array}{l}\text { chemical } \\
\text { compound, } \\
\text { drug }\end{array}$ & Ciliobrevin-D & Millipore Sigma & 250401 & $30 \mu \mathrm{M}$ \\
\hline $\begin{array}{l}\text { chemical } \\
\text { compound, } \\
\text { drug }\end{array}$ & {$[3 \mathrm{H}] \mathrm{GDP}$} & $\begin{array}{l}\text { PerkinEImer Life } \\
\text { Sciences }\end{array}$ & NET966 & $\begin{array}{l}3,000 \\
\mathrm{cpm} / \mathrm{pmol}\end{array}$ \\
\hline $\begin{array}{l}\text { chemical } \\
\text { compound, } \\
\text { drug }\end{array}$ & GTPgS35 & $\begin{array}{l}\text { PerkinElmer Life } \\
\text { Sciences }\end{array}$ & $\mathrm{NEG030H}$ & \\
\hline $\begin{array}{l}\text { Software, } \\
\text { algorithm }\end{array}$ & $\begin{array}{l}\text { ImageJ } \\
\text { software }\end{array}$ & $\begin{array}{l}\text { ImageJ } \\
\text { (http://imagej.nih } \\
. \text { gov/ij/) }\end{array}$ & $\begin{array}{l}\text { ImageJ, } \\
\text { RRID:SCR_00307 } \\
0\end{array}$ & \\
\hline
\end{tabular}




\begin{tabular}{|l|l|l|l|l|}
\hline Software, & $\begin{array}{l}\text { GraphPad } \\
\text { algorithm }\end{array}$ & $\begin{array}{l}\text { GraphPad Prism } \\
\text { Prism } \\
\text { software }\end{array}$ & $\begin{array}{l}\text { GraphPad Prism, } \\
\text { d.com) }\end{array}$ & $\begin{array}{l}\text { Version } \\
\text { RRID:SCR_00279 }\end{array}$ \\
\hline
\end{tabular}

\section{Methods}

429 Protein purification and ARL3 GEF assay

430 Plasmids directing the expression of mouse GST-ARL13B or GST-ARL13B ${ }^{\text {V358A }}$

431 proteins were transiently transfected into HEK cells and the recombinant proteins were

432 later purified by affinity chromatography using glutathione-Sepharose, as described

433 previously (Cavenagh et al. 1994; Ivanova et al. 2017). Human ARL3 (98.4\% identical

434 to mouse ARL3) was expressed in BL21 bacteria and purified as previously described

435 (Van Valkenburgh et al. 2001). The ARL3 GEF assay was performed as previously

436 described (Ivanova et al. 2017). Briefly, ARL3 $(10 \mu \mathrm{M})$ was pre-incubated with $\left[{ }^{3} \mathrm{H}\right] \mathrm{GDP}$

$437(1 \mu \mathrm{M}$; PerkinElmer Life Sciences, specific activity $\sim 3,000 \mathrm{cpm} / \mathrm{pmol})$ for $1 \mathrm{~h}$ at $30^{\circ} \mathrm{C}$ in

$43825 \mathrm{mM}$ HEPES, $\mathrm{pH} 7.4,100 \mathrm{mM} \mathrm{NaCl}, 10 \mathrm{mM} \mathrm{MgCl}$. In contrast, pre-loading of

439 ARL13B $(10 \mu \mathrm{M})$ was achieved by incubation in $100 \mu \mathrm{M}$ GTP $\gamma$ for $1 \mathrm{~min}$ at room

440 temperature, due to its much more rapid exchange kinetics. The GEF assay was

441 initiated upon addition of ARL3 (final $=1 \mu \mathrm{M}$ ), ARL13B (final $=0$ or $1 \mu \mathrm{M}$ ), $10 \mu \mathrm{M}$ GTP $\gamma$,

442 and $100 \mu \mathrm{M}$ GDP (to prevent re-binding of any released $\left[{ }^{3} \mathrm{H}\right] \mathrm{GDP}$ ), in a final volume of

$443100 \mu \mathrm{L}$. The intrinsic rate of GDP dissociation from ARL3 was determined in parallel as

444 that released in the absence of any added ARL13B. The reactions were stopped at

445 different times (0-15 $\mathrm{min}$ ) by dilution of $10 \mu \mathrm{L}$ of the reaction mixture into $2 \mathrm{ml}$ of ice-cold

446 buffer (20 mM Tris, $\mathrm{pH} 7.5,100 \mathrm{mM} \mathrm{NaCl}, 10 \mathrm{mM} \mathrm{MgCl}_{2}, 1 \mathrm{mM}$ dithiothreitol). The

447 amount of ARL3-bound $\left[{ }^{3} \mathrm{H}\right] \mathrm{GDP}$ was determined by rapid filtration through BA85 
448 nitrocellulose filters $(0.45 \mu \mathrm{m}, 25 \mathrm{~mm}$, Whatman), with $3 \times 2 \mathrm{~mL}$ washes, and quantified

449 using liquid scintillation counting. Time points are routinely collected in at least duplicate

450 and each experiment reported was repeated at least twice, yielding very similar results.

451 Data were analyzed in GraphPad Prism 7 software.

Mouse allele generation and identification

All mice were cared for in accordance with NIH guidelines and Emory's

455 Institutional Animal Care and Use Committee (IACUC). Lines used were Arl13bV358A

456 (Arl13bem1Tc) [MGl: 6256969], Arl13b

457 Laboratory). To generate the V358A point mutation in the mouse, a CRISPR gRNA

458 (CCAGTCAATACAGACGAGTCTA) targeting exon 8 of the Arl13b locus along with a

459 donor oligo (5'-

460 CCTATATTCTTCTAGAAAACAGTAAGAAGAAAACCAAGAAACTACGAATGAAAAGGA

461 GTCATCGGGㅡAGAACCAGTㅡAATACAGACGAGTCTACTCCAAAGAGTCCCACGCC

462 TCCCCAAC-3'; underlined bases are engineered) were designed to generate a T-to-C

463 change creating the V358A point mutation and C-to-G change creating a TspRI

464 restriction site that could be used for genotyping (Millipore Sigma). The gRNA (50

$465 \mathrm{ng} / \mu \mathrm{l})$, oligo donor (50 $\mathrm{ng} / \mu \mathrm{l})$ and CRISPR protein $(100 \mathrm{ng} / \mu \mathrm{L})$ were injected by the

466 Emory Transgenic and Gene Targeting core into one-cell C57BI/6J zygotes. Zygotes

467 were cultured to 2-cell before being transferred to pseudopregnant females. Genomic

468 tail DNA from resulting offspring was amplified using PCR primers (5'-

469 GAAGCAGGCATGGTGGTAAT-3' \& 5'-TGAACCGCTAATGGGAAATC-3') located

470 upstream and downstream of the donor oligo breakpoints. The products were 
471 sequenced (5'-GAAGCAGGCATGGTGGTAAT-3') and 2 animals were identified

472 heterozygous for the desired change and with no additional editing. One line (\#173) was

473 bred to FVB/NJ for three generations prior to performing any phenotypic analysis. Males

474 from at least two distinct meiotic recombination opportunities were used in each

475 generation that to minimize potential confounds associated with off-target

476 CRISPR/Cas9 editing.

477 Genotyping was performed on DNA extracted from ear punch or yolk sac via

478 PCR using the following primers: Fwd: 5'- AAGAATGAAAAGGAGTCAGCG -3', Rev: 5'-

479 TGAACCGCTAATGGGAAACT -3'; a SNP was engineered in the forward primer that, in

480 combination with the V358A mutation, created a Cac8I restriction site. Thus, the PCR

481 product was digested with Cac8I enzyme, run out on a 4\% agarose gel and the relevant

482 bands were detected: undigested wild type ( 192bp) and digested mutant bands

483 ( 171bp).

484

485 Phenotypic analysis of embryos

486 Timed matings of heterozygous intercrosses were performed to generate embryos of

487 the indicated stage, with somite-matched pairs examined at each stage when

488 appropriate. Embryos were dissected in cold phosphate-buffered saline and processed

489 for immunofluorescence staining as previously described (Horner et al. 2011).

$491 \quad$ Mouse embryonic fibroblasts

492 Mouse embryonic fibroblasts (MEFs) were isolated and immortalized as previously

493 described (Mariani et al. 2016). The identity of all cell lines were confirmed by 
494 genotyping PCR and tested mycoplasma negative. MEFs were maintained in DMEM

495 with $10 \%$ fetal bovine serum (FBS) and $1 \%$ penicillin/streptomycin at $37^{\circ} \mathrm{C}$ in $5 \% \mathrm{CO}_{2}$.

496 For experimental use, $A r l 13 b^{+/+}, A r l 13 b^{V 358 A /+}$, and $A r l 13 b^{V 358 A / V 358 A}$ and $A r l 13 b^{h n n / h n n}$

497 MEFs were grown on coverslips at a density of $0.5 \times 10^{6}$ cells $/ \mathrm{mL}$ and treated for $24 \mathrm{~h}$

498 with $0.5 \%$ FBS Shh conditioned media or $0.5 \%$ FBS media to induce ciliogenesis

499 (Larkins et al. 2011).

500

501 Antibodies

502 Primary antibodies used were: mouse anti-Shh (5E1), mouse anti-Nkx2.2 (74.5A5),

503 mouse anti-HB9 (81.5C10), mouse anti-Nkx6.1 (F55A10) (1:5 Developmental Studies

504 Hybridoma Bank); rabbit anti-Olig2 (1:300 Millipore AB9610); mouse anti-acetylated $\alpha$ -

505 tubulin (1:2500 Millipore Sigma; T6793), mouse anti-ARL13B (1:1000 NeuroMab

506 N295B/66), rabbit anti-ARL13B (1:1000, Protein Tech 17711-1-AP); rabbit anti-ARL13B

507 sera from 3 distinct rabbits (503, 504 and 505) (Caspary Lab (Caspary et al. 2007)),

508 rabbit anti-Smoothened (1:1000, kindly provided by K. Anderson); rabbit anti-IFT88

509 (1:1000, kindly provided by B. Yoder); rabbit anti-ARL3 (1:1000, (Cavenagh et al.

510 1994)); rabbit anti- INPP5E (1:150, Protein Tech 17797-1-AP); guinea pig anti-Gli2

511 (1:200, kindly provided by J. Eggenschwiler); rabbit anti-Ptch1 (1:150, kindly provided

512 by R. Rohatgi), goat anti-Sufu (1:100, SC10933, Santa Cruz); goat anti-Gli3 (1:200,

513 R\&D AF3690); Alexa Fluor 488 and Alexa Fluor 568 (1:300, ThermoFisher); and

514 Hoechst nuclear stain (1:3000). In all depicted images the red channel is false colored

515 as magenta for the benefit of readers. 


\section{Image Quantification}

518 Fluorescent intensities were measured in ImageJ software. Cilia were first identified by

519 positive acetylated $\alpha$-tubulin and an outline was hand drawn around the length of the

520 cilium. The channel was switched to the protein of interest and a measurement of the

521 average fluorescent intensity was acquired. The same outline was then used to acquire

522 a background reading of the cell-body that most closely matched the background at the

523 cilium. In all cases immunofluorescent averages of proteins of interest in cilia were

524 normalized to cell-body intensities (Figure 3 - Figure supplement 1). For samples with

525 antibodies targeting Gli2, Gli3, and Sufu the ciliary tip was isolated and measured. The

526 cilia tip was identified by weak acetylated $\alpha$-tubulin staining or the cilium base was

527 identified by the presence of the acetylated $\alpha$-tubulin positive fibrils in the cell body that

528 cluster at the base of the cilium (Larkins et al. 2011). For samples with antibodies

529 targeting Smo, Ptch1, ARL3, and INPP5E the entire cilium was measured. We plotted

530 the ratio of fluorescence intensity of the protein of interest to the cell body background

531 as violin plots. Within each plot the dashed lines represent the median and interquartile

532 range. The number of cilia examined per genotype and per condition are listed below

533 their respective plot. All data, except for Smo which varied both genotype and

534 treatment, were analyzed by one-way ANOVA. In the event of a significant ANOVA,

535 Tukey's multiple comparisons were employed to determine significance as all groups

536 were compared. Smo fluorescent intensity data were analyzed by two-way ANOVA. As

537 only specific groups were compared, the significance of those comparisons across and

538 between groups were made using Sidak's post-hoc to not inflate the significance of

539 those comparisons Data were analyzed in GraphPad Prism 7 software. 
In a similar experiment, retrograde IFT was inhibited by the addition of $30 \mu \mathrm{M}$

541 ciliobrevin-D (Millipore Sigma; 250401) or 0.1\% DMSO control in low-serum media for

54260 min after ciliation was induced by serum starvation for $24 \mathrm{~h}$ prior with $0.5 \%$ FBS

543 media. Cilia were identified by staining with antibodies directed against acetylated $\alpha$ -

544 tubulin, IFT88, and ARL13B. Fluorescent intensities were measured in ImageJ software.

545 Again, cilia were first identified by positive acetylated $\alpha$-tubulin and an outline was hand

546 drawn. The channel was switched to the protein of interest and a measurement of the

547 average fluorescent intensity was acquired. The same outline was then used to acquire

548 a background reading of the cell-body. To measure IFT88, the cilia tip was identified by

549 weak acetylated $\alpha$-tubulin staining or the cilium base was identified by the presence of

550 acetylated $\alpha$-tubulin fibrils in the cell body that cluster at the base of the cilium (Larkins

551 et al. 2011). To make comparisons among cell lines of distinct genotype with and

552 without ciliobrevin-D treatment, data were analyzed by two-way ANOVA. To analyze the

553 specific differences across groups, multiple comparisons were made using Sidak's post-

554 hoc.

Western Blots

557 Western blotting was performed as previously described (Mariani et al. 2016), with

558 antibody against ARL13B (1:1000 Neuromab N295B/66). Lysates were prepared with

559 RIPA buffer and SigmaFast protease inhibitors (Nachtergaele et al. 2013). Values

560 presented as volume intensity measured by chemiluminescence detected on ChemiDoc

561 Touch Imaging System were normalized to total protein as measured on a stain-free gel

562 (Thacker et al. 2016; Rivero-Gutierrez et al. 2014). Normalized values were analyzed by 
563 one-way ANOVA and Tukey's multiple comparisons. Data were analyzed in GraphPad

564 Prism 7 software.

565

566 Materials in this manuscript are available, those interested should contract the

567 corresponding author.

569 Acknowledgements

570 This work was supported by funding from NIH grants R01NS090029 and R35GM122549 to T.C.

571 and R35GM122568 to R.A.K. E.D.G. was supported by NIH training grant T32NS096050 and a

572 diversity supplement to R01NS090029. Further support came from the Emory Integrated Mouse

573 Transgenic and Gene Targeting Core, which is subsidized by the Emory University School of

574 Medicine and with support by the Georgia Clinical \& Translational Science Alliance of the

575 National Institutes of Health under Award Number UL1TR002378 as well as the Emory

576 University Integrated Cellular Imaging Microscopy Core of the Emory Neuroscience NINDS

577 Core Facilities grant, P30NS055077. We are grateful to Alyssa Long and Sarah Suciu for

578 sequencing potential CRISPR founders, and to members of the Caspary lab for discussion and

579 manuscript comments.

\section{Competing Interests}

580 The authors have no competing interests to disclose. 


\section{References}

Aza-Blanc, P., H. Y. Lin, A. Ruiz i Altaba, and T. B. Kornberg. 2000. 'Expression of the vertebrate Gli proteins in Drosophila reveals a distribution of activator and repressor activities', Development, 127: 4293-301.

Bangs, F. K., N. Schrode, A. K. Hadjantonakis, and K. V. Anderson. 2015. 'Lineage specificity of primary cilia in the mouse embryo', Nat Cell Biol, 17: 113-22.

Barral, D. C., S. Garg, C. Casalou, G. F. Watts, J. L. Sandoval, J. S. Ramalho, V. W. Hsu, and M. B. Brenner. 2012. 'Arl13b regulates endocytic recycling traffic', Proc Natl Acad Sci U $S$ A, 109: 21354-9.

Bay, S. N., A. B. Long, and T. Caspary. 2018. 'Disruption of the ciliary GTPase Arl13b suppresses Sonic hedgehog overactivation and inhibits medulloblastoma formation', Proc Natl Acad Sci U S A, 115: 1570-75.

Briscoe, J., Y. Chen, T. M. Jessell, and G. Struhl. 2001. 'A hedgehog-insensitive form of patched provides evidence for direct long-range morphogen activity of sonic hedgehog in the neural tube', Mol Cell, 7: 1279-91.

Briscoe, J., and P. P. Therond. 2013. 'The mechanisms of Hedgehog signalling and its roles in development and disease', Nat Rev Mol Cell Biol, 14: 416-29.

Casalou, C., C. Seixas, A. Portelinha, P. Pintado, M. Barros, J. S. Ramalho, S. S. Lopes, and D. C. Barral. 2014. 'Arl13b and the non-muscle myosin heavy chain IIA are required for circular dorsal ruffle formation and cell migration', J Cell Sci, 127: 2709-22.

Caspary, T., C. E. Larkins, and K. V. Anderson. 2007. 'The graded response to Sonic Hedgehog depends on cilia architecture', Dev Cell, 12: 767-78.

Cavenagh, M. M., M. Breiner, A. Schurmann, A. G. Rosenwald, T. Terui, C. Zhang, P. A. Randazzo, M. Adams, H. G. Joost, and R. A. Kahn. 1994. 'ADP-ribosylation factor (ARF)-like 3, a new member of the ARF family of GTP-binding proteins cloned from human and rat tissues', J Biol Chem, 269: 18937-42.

Cevik, S., Y. Hori, O. I. Kaplan, K. Kida, T. Toivenon, C. Foley-Fisher, D. Cottell, T. Katada, K. Kontani, and O. E. Blacque. 2010. 'Joubert syndrome Arl13b functions at ciliary membranes and stabilizes protein transport in Caenorhabditis elegans', J Cell Biol, 188: 953-69.

Cevik, S., A. A. Sanders, E. Van Wijk, K. Boldt, L. Clarke, J. van Reeuwijk, Y. Hori, N. Horn, L. Hetterschijt, A. Wdowicz, A. Mullins, K. Kida, O. I. Kaplan, S. E. van Beersum, K. Man Wu, S. J. Letteboer, D. A. Mans, T. Katada, K. Kontani, M. Ueffing, R. Roepman, H. Kremer, and O. E. Blacque. 2013. 'Active transport and diffusion barriers restrict Joubert Syndrome-associated ARL13B/ARL-13 to an Inv-like ciliary membrane subdomain', PLoS Genet, 9: e1003977.

Chavez, M., S. Ena, J. Van Sande, A. de Kerchove d'Exaerde, S. Schurmans, and S. N. Schiffmann. 2015. 'Modulation of Ciliary Phosphoinositide Content Regulates Trafficking and Sonic Hedgehog Signaling Output', Dev Cell, 34: 338-50.

Chiang, C., Y. Litingtung, E. Lee, K. E. Young, J. L. Corden, H. Westphal, and P. A. Beachy. 1996. 'Cyclopia and defective axial patterning in mice lacking Sonic hedgehog gene function', Nature, 383: 407-13.

Consortium, C. elegans Sequencing. 1998. 'Genome sequence of the nematode C. elegans: a platform for investigating biology', Science, 282: 2012-8.

Corbit, K. C., P. Aanstad, V. Singla, A. R. Norman, D. Y. Stainier, and J. F. Reiter. 2005. 'Vertebrate Smoothened functions at the primary cilium', Nature, 437: 1018-21. 
Cortellino, S., C. Wang, B. Wang, M. R. Bassi, E. Caretti, D. Champeval, A. Calmont, M. Jarnik, J. Burch, K. S. Zaret, L. Larue, and A. Bellacosa. 2009. 'Defective ciliogenesis, embryonic lethality and severe impairment of the Sonic Hedgehog pathway caused by inactivation of the mouse complex A intraflagellar transport gene Ift122/Wdr10, partially overlapping with the DNA repair gene Med1/Mbd4', Dev Biol, 325: 225-37.

D'Souza-Schorey, C., and P. Chavrier. 2006. 'ARF proteins: roles in membrane traffic and beyond', Nat Rev Mol Cell Biol, 7: 347-58.

Dessaud, E., L. L. Yang, K. Hill, B. Cox, F. Ulloa, A. Ribeiro, A. Mynett, B. G. Novitch, and J. Briscoe. 2007. 'Interpretation of the sonic hedgehog morphogen gradient by a temporal adaptation mechanism', Nature, 450: 717-20.

Dyson, J. M., S. E. Conduit, S. J. Feeney, S. Hakim, T. DiTommaso, A. J. Fulcher, A. Sriratana, G. Ramm, K. A. Horan, R. Gurung, C. Wicking, I. Smyth, and C. A. Mitchell. 2017. 'INPP5E regulates phosphoinositide-dependent cilia transition zone function', J Cell Biol, 216: 247-63.

East, M. P., J. B. Bowzard, J. B. Dacks, and R. A. Kahn. 2012. 'ELMO domains, evolutionary and functional characterization of a novel GTPase-activating protein (GAP) domain for Arf protein family GTPases', J Biol Chem, 287: 39538-53.

Firestone, A. J., J. S. Weinger, M. Maldonado, K. Barlan, L. D. Langston, M. O'Donnell, V. I. Gelfand, T. M. Kapoor, and J. K. Chen. 2012. 'Small-molecule inhibitors of the AAA+ ATPase motor cytoplasmic dynein', Nature, 484: 125-9.

Garcia-Gonzalo, F. R., S. C. Phua, E. C. Roberson, G. Garcia, 3rd, M. Abedin, S. Schurmans, T. Inoue, and J. F. Reiter. 2015. 'Phosphoinositides Regulate Ciliary Protein Trafficking to Modulate Hedgehog Signaling', Dev Cell, 34: 400-09.

Goetz, S. C., P. J. Ocbina, and K. V. Anderson. 2009. 'The primary cilium as a Hedgehog signal transduction machine', Methods Cell Biol, 94: 199-222.

Gotthardt, K., M. Lokaj, C. Koerner, N. Falk, A. Giessl, and A. Wittinghofer. 2015. 'A G-protein activation cascade from Arl13B to Arl3 and implications for ciliary targeting of lipidated proteins', Elife, 4.

Hanke-Gogokhia, C., Z. Wu, C. D. Gerstner, J. M. Frederick, H. Zhang, and W. Baehr. 2016. 'Arf-like Protein 3 (ARL3) Regulates Protein Trafficking and Ciliogenesis in Mouse Photoreceptors', J Biol Chem, 291: 7142-55.

Haycraft, C. J., B. Banizs, Y. Aydin-Son, Q. Zhang, E. J. Michaud, and B. K. Yoder. 2005. 'Gli2 and Gli3 localize to cilia and require the intraflagellar transport protein polaris for processing and function', PLoS Genet, 1: e53.

Higginbotham, H., T. Y. Eom, L. E. Mariani, A. Bachleda, J. Hirt, V. Gukassyan, C. L. Cusack, C. Lai, T. Caspary, and E. S. Anton. 2012. 'Arl13b in primary cilia regulates the migration and placement of interneurons in the developing cerebral cortex', Dev Cell, 23: 925-38.

Hori, Y., T. Kobayashi, Y. Kikko, K. Kontani, and T. Katada. 2008. 'Domain architecture of the atypical Arf-family GTPase Arl13b involved in cilia formation', Biochem Biophys Res Commun, 373: 119-24.

Horner, V. L., and T. Caspary. 2011. 'Disrupted dorsal neural tube BMP signaling in the cilia mutant Arl13b hnn stems from abnormal Shh signaling', Dev Biol, 355: 43-54.

Houde, C., R. J. Dickinson, V. M. Houtzager, R. Cullum, R. Montpetit, M. Metzler, E. M. Simpson, S. Roy, M. R. Hayden, P. A. Hoodless, and D. W. Nicholson. 2006. 'Hippi is essential for node cilia assembly and Sonic hedgehog signaling', Dev Biol, 300: 523-33. 
Huangfu, D., and K. V. Anderson. 2005. 'Cilia and Hedgehog responsiveness in the mouse', Proc Natl Acad Sci U S A, 102: 11325-30.

Huangfu, D., A. Liu, A. S. Rakeman, N. S. Murcia, L. Niswander, and K. V. Anderson. 2003. 'Hedgehog signalling in the mouse requires intraflagellar transport proteins', Nature, 426: 83-7.

Huangfu, Danwei, and Kathryn V Anderson. 2006. 'Signaling from Smo to Ci/Gli: conservation and divergence of Hedgehog pathways from Drosophila to vertebrates', Development, 133: 3-14.

Humbert, M. C., K. Weihbrecht, C. C. Searby, Y. Li, R. M. Pope, V. C. Sheffield, and S. Seo. 2012. 'ARL13B, PDE6D, and CEP164 form a functional network for INPP5E ciliary targeting', Proc Natl Acad Sci U S A, 109: 19691-6.

Humke, E. W., K. V. Dorn, L. Milenkovic, M. P. Scott, and R. Rohatgi. 2010. 'The output of Hedgehog signaling is controlled by the dynamic association between Suppressor of Fused and the Gli proteins', Genes Dev, 24: 670-82.

Ingham, P. W., Y. Nakano, and C. Seger. 2011. 'Mechanisms and functions of Hedgehog signalling across the metazoa', Nat Rev Genet, 12: 393-406.

Ivanova, A. A., T. Caspary, N. T. Seyfried, D. M. Duong, A. B. West, Z. Liu, and R. A. Kahn. 2017. 'Biochemical characterization of purified mammalian ARL13B protein indicates that it is an atypical GTPase and ARL3 guanine nucleotide exchange factor (GEF)', $J$ Biol Chem, 292: 11091-108.

Kahn, R. A., E. Bruford, H. Inoue, J. M. Logsdon, Jr., Z. Nie, R. T. Premont, P. A. Randazzo, M. Satake, A. B. Theibert, M. L. Zapp, and D. Cassel. 2008. 'Consensus nomenclature for the human ArfGAP domain-containing proteins', J Cell Biol, 182: 1039-44.

Kim, J., M. Kato, and P. A. Beachy. 2009. 'Gli2 trafficking links Hedgehog-dependent activation of Smoothened in the primary cilium to transcriptional activation in the nucleus', Proc Natl Acad Sci U S A, 106: 21666-71.

Kong, J. H., C. Siebold, and R. Rohatgi. 2019. 'Biochemical mechanisms of vertebrate hedgehog signaling', Development, 146.

Kuwabara, P. E., M. H. Lee, T. Schedl, and G. S. Jefferis. 2000. 'A C. elegans patched gene, ptc1, functions in germ-line cytokinesis', Genes Dev, 14: 1933-44.

Larkins, C. E., G. D. Aviles, M. P. East, R. A. Kahn, and T. Caspary. 2011. 'Arl13b regulates ciliogenesis and the dynamic localization of Shh signaling proteins', Mol Biol Cell, 22: 4694-703.

Li, Y., W. G. Kelly, J. M. Logsdon, Jr., A. M. Schurko, B. D. Harfe, K. L. Hill-Harfe, and R. A. Kahn. 2004. 'Functional genomic analysis of the ADP-ribosylation factor family of GTPases: phylogeny among diverse eukaryotes and function in C. elegans', FASEB J, 18: 1834-50.

Li, Y., Q. Wei, Y. Zhang, K. Ling, and J. Hu. 2010. 'The small GTPases ARL-13 and ARL-3 coordinate intraflagellar transport and ciliogenesis', J Cell Biol, 189: 1039-51.

Liem, K. F., Jr., A. Ashe, M. He, P. Satir, J. Moran, D. Beier, C. Wicking, and K. V. Anderson. 2012. 'The IFT-A complex regulates Shh signaling through cilia structure and membrane protein trafficking', J Cell Biol, 197: 789-800.

Liem, K. F., Jr., M. He, P. J. Ocbina, and K. V. Anderson. 2009. 'Mouse Kif7/Costal2 is a ciliaassociated protein that regulates Sonic hedgehog signaling', Proc Natl Acad Sci U S A, 106: $13377-82$. 
Lim, Y. S., C. E. Chua, and B. L. Tang. 2011. 'Rabs and other small GTPases in ciliary transport', Biol Cell, 103: 209-21.

Liu, A., B. Wang, and L. A. Niswander. 2005. 'Mouse intraflagellar transport proteins regulate both the activator and repressor functions of Gli transcription factors', Development, 132: 3103-11.

Logsdon, J. M., Jr., and R. A. Kahn (ed.)^(eds.). 2004. Arf Family GTPases. In: Kahn RA, editor.

Lu, H., M. T. Toh, V. Narasimhan, S. K. Thamilselvam, S. P. Choksi, and S. Roy. 2015. 'A function for the Joubert syndrome protein Arl13b in ciliary membrane extension and ciliary length regulation', Dev Biol, 397: 225-36.

Mariani, L. E., M. F. Bijlsma, A. I. Ivanova, S. K. Suciu, R. A. Kahn, and T. Caspary. 2016. 'Arl13b regulates Shh signaling from both inside and outside the cilium', Mol Biol Cell.

Miertzschke, M., C. Koerner, M. Spoerner, and A. Wittinghofer. 2014. 'Structural insights into the small G-protein Arl13B and implications for Joubert syndrome', Biochem J, 457: 30111 .

Milenkovic, L., M. P. Scott, and R. Rohatgi. 2009. 'Lateral transport of Smoothened from the plasma membrane to the membrane of the cilium', J Cell Biol, 187: 365-74.

Murdoch, J. N., and A. J. Copp. 2010. 'The relationship between sonic Hedgehog signaling, cilia, and neural tube defects', Birth Defects Res A Clin Mol Teratol, 88: 633-52.

Murray, S. A., J. L. Morgan, C. Kane, Y. Sharma, C. S. Heffner, J. Lake, and L. R. Donahue. 2010. 'Mouse gestation length is genetically determined', PLoS One, 5: e12418.

Nachtergaele, S., D. M. Whalen, L. K. Mydock, Z. Zhao, T. Malinauskas, K. Krishnan, P. W. Ingham, D. F. Covey, C. Siebold, and R. Rohatgi. 2013. 'Structure and function of the Smoothened extracellular domain in vertebrate Hedgehog signaling', Elife, 2: e01340.

Nozaki, S., Y. Katoh, M. Terada, S. Michisaka, T. Funabashi, S. Takahashi, K. Kontani, and K. Nakayama. 2017. 'Regulation of ciliary retrograde protein trafficking by the Joubert syndrome proteins ARL13B and INPP5E', J Cell Sci, 130: 563-76.

Nusslein-Volhard, C., and E. Wieschaus. 1980. 'Mutations affecting segment number and polarity in Drosophila', Nature, 287: 795-801.

Placzek, M., and J. Briscoe. 2018. 'Sonic hedgehog in vertebrate neural tube development', Int J Dev Biol, 62: 225-34.

Raleigh, D. R., and J. F. Reiter. 2019. 'Misactivation of Hedgehog signaling causes inherited and sporadic cancers', J Clin Invest, 129: 465-75.

Revenkova, E., Q. Liu, G. L. Gusella, and C. Iomini. 2018. 'The Joubert syndrome protein ARL13B binds tubulin to maintain uniform distribution of proteins along the ciliary membrane', J Cell Sci, 131.

Rink, J. C., K. A. Gurley, S. A. Elliott, and A. Sanchez Alvarado. 2009. 'Planarian Hh signaling regulates regeneration polarity and links Hh pathway evolution to cilia', Science, 326: 1406-10.

Rivero-Gutierrez, B., A. Anzola, O. Martinez-Augustin, and F. S. de Medina. 2014. 'Stain-free detection as loading control alternative to Ponceau and housekeeping protein immunodetection in Western blotting', Anal Biochem, 467: 1-3.

Roelink, H., A. Augsburger, J. Heemskerk, V. Korzh, S. Norlin, A. Ruiz i Altaba, Y. Tanabe, M. Placzek, T. Edlund, T. M. Jessell, and et al. 1994. 'Floor plate and motor neuron induction by vhh-1, a vertebrate homolog of hedgehog expressed by the notochord', Cell, 76: 761-75. 
Rohatgi, R., L. Milenkovic, and M. P. Scott. 2007. 'Patched1 regulates hedgehog signaling at the primary cilium', Science, 317: 372-6.

Roy, S. 2012. 'Cilia and Hedgehog: when and how was their marriage solemnized?', Differentiation, 83: S43-8.

Ruiz i Altaba, A. 1998. 'Combinatorial Gli gene function in floor plate and neuronal inductions by Sonic hedgehog', Development, 125: 2203-12.

Schlacht, A., K. Mowbrey, M. Elias, R. A. Kahn, and J. B. Dacks. 2013. 'Ancient complexity, opisthokont plasticity, and discovery of the 11th subfamily of Arf GAP proteins', Traffic, 14: 636-49.

Seixas, C., S. Y. Choi, N. Polgar, N. L. Umberger, M. P. East, X. Zuo, H. Moreiras, R. Ghossoub, A. Benmerah, R. A. Kahn, B. Fogelgren, T. Caspary, J. H. Lipschutz, and D. C. Barral. 2016. 'Arl13b and the exocyst interact synergistically in ciliogenesis', Mol Biol Cell, 27: 308-20.

Sigg, Monika Abedin, Tabea Menchen, Chanjae Lee, Jeffery Johnson, Melissa K Jungnickel, Semil P Choksi, Galo Garcia 3rd, Henriette Busengdal, Gerard W Dougherty, and Petra Pennekamp. 2017. 'Evolutionary proteomics uncovers ancient associations of cilia with signaling pathways', Developmental cell, 43: 744-62. e11.

Stolc, V., M. P. Samanta, W. Tongprasit, and W. F. Marshall. 2005. 'Genome-wide transcriptional analysis of flagellar regeneration in Chlamydomonas reinhardtii identifies orthologs of ciliary disease genes', Proc Natl Acad Sci U S A, 102: 3703-7.

Sztul, E., P. W. Chen, J. E. Casanova, J. Cherfils, J. B. Dacks, D. G. Lambright, F. S. Lee, P. A. Randazzo, L. C. Santy, A. Schurmann, I. Wilhelmi, M. E. Yohe, and R. A. Kahn. 2019. 'ARF GTPases and their GEFs and GAPs: concepts and challenges', Mol Biol Cell, 30: 1249-71.

Taylor, S. P., T. J. Dantas, I. Duran, S. Wu, R. S. Lachman, Consortium University of Washington Center for Mendelian Genomics, S. F. Nelson, D. H. Cohn, R. B. Vallee, and D. Krakow. 2015. 'Mutations in DYNC2LI1 disrupt cilia function and cause short rib polydactyly syndrome', Nat Commun, 6: 7092.

Thacker, J. S., D. H. Yeung, W. R. Staines, and J. G. Mielke. 2016. 'Total protein or highabundance protein: Which offers the best loading control for Western blotting?', Anal Biochem, 496: 76-8.

Tran, P. V., C. J. Haycraft, T. Y. Besschetnova, A. Turbe-Doan, R. W. Stottmann, B. J. Herron, A. L. Chesebro, H. Qiu, P. J. Scherz, J. V. Shah, B. K. Yoder, and D. R. Beier. 2008. 'THM1 negatively modulates mouse sonic hedgehog signal transduction and affects retrograde intraflagellar transport in cilia', Nat Genet, 40: 403-10.

Tuz, K., R. Bachmann-Gagescu, D. R. O'Day, K. Hua, C. R. Isabella, I. G. Phelps, A. E. Stolarski, B. J. O'Roak, J. C. Dempsey, C. Lourenco, A. Alswaid, C. G. Bonnemann, L. Medne, S. Nampoothiri, Z. Stark, R. J. Leventer, M. Topcu, A. Cansu, S. Jagadeesh, S. Done, G. E. Ishak, I. A. Glass, J. Shendure, S. C. Neuhauss, C. R. Haldeman-Englert, D. Doherty, and R. J. Ferland. 2014. 'Mutations in CSPP1 cause primary cilia abnormalities and Joubert syndrome with or without Jeune asphyxiating thoracic dystrophy', Am J Hum Genet, 94: 62-72.

Van Valkenburgh, H., J. F. Shern, J. D. Sharer, X. Zhu, and R. A. Kahn. 2001. 'ADP-ribosylation factors (ARFs) and ARF-like 1 (ARL1) have both specific and shared effectors: characterizing ARL1-binding proteins', J Biol Chem, 276: 22826-37. 
Wang, Y., Z. Zhou, C. T. Walsh, and A. P. McMahon. 2009. 'Selective translocation of intracellular Smoothened to the primary cilium in response to Hedgehog pathway modulation', Proc Natl Acad Sci U S A, 106: 2623-8.

810 Warner, J. F., A. M. McCarthy, R. L. Morris, and D. R. McClay. 2014. 'Hedgehog signaling requires motile cilia in the sea urchin', Mol Biol Evol, 31: 18-22. 'Kinetics of hedgehog-dependent full-length Gli3 accumulation in primary cilia and subsequent degradation', Mol Cell Biol, 30: 1910-22.

Zhang, Q., Y. Li, Y. Zhang, V. E. Torres, P. C. Harris, K. Ling, and J. Hu. 2016. 'GTP-binding of ARL-3 is activated by ARL-13 as a GEF and stabilized by UNC-119', Sci Rep, 6: 24534.

820

Zugasti, O., J. Rajan, and P. E. Kuwabara. 2005. 'The function and expansion of the Patched- and Hedgehog-related homologs in C. elegans', Genome Res, 15: 1402-10. 


\section{Figure Legends}

\section{Figure 1.}

821 ARL3 GEF activity is retained in the ARL13B ${ }^{\text {V358A }}$ mutant. Time course of the

822 release of pre-bound $\left[{ }^{3} \mathrm{H}\right] \mathrm{GDP}$ from purified, recombinant ARL3 in the absence (ARL3)

823 or presence of mouse wild type ARL13B or ARL13B ${ }^{\mathrm{V} 358 \mathrm{~A}}$ (mARL13B) are shown. See

824 Methods for details. Error bars \pm standard deviation.

\section{Figure 2.}

Generation of the Arl13b $b^{1358 A / V 358 A}$ mouse.

826 (A) Schematic of Arl13b gene and donor oligo (orange bar) at exon 8 used to generate

827 the V358A causing point mutation. Arrows indicate primers used for allele validation. (B)

828 Arl13b DNA and relevant amino acid sequence with the RVEP sequence in the orange

829 box and the T-to-C mutation highlighted in pink. (C) Confocal images of cilia marker

830 IFT88 (green) and ARL13B (magenta; NeuroMab) staining in neural tube of E10.5

831 somite-matched embryos. ARL13B-positive cilia are visible in $\mathrm{Arl13b^{+/+ }}$ and

$832 A r l 13 b^{V 358 A+}$, but not in Arl1 $b^{V 358 A / V 358 A}$ embryos. (See Figure 2 - Figure supplement 1

833 for images of neural tube cilia under saturating conditions.) At least 5 embryos per

834 genotype across five litters were examined. Scale bars are $50 \mu \mathrm{m}$. (D) ARL13B Western

835 blot of E10.5 whole embryo lysates, wild type $(+/+), \operatorname{Arl13} b^{V 358 A /+}(A /+)$ and

$836 A r / 13 b^{V 358 A / V 358 A}(A / A)$ and $(E)$ quantification presented as average intensity normalized

837 to total protein \pm standard deviation. Representative blot of whole embryo lysates $(n=3$

838 embryos per genotype with technical duplicate of each). ${ }^{*} p<0.05$, one-way ANOVA

839 and Tukey's multiple comparison. 


\section{Figure 3.}

840 ARL13B $^{\mathrm{V} 358 \mathrm{~A}}$ is undetectable in cilia and cannot be enriched by inhibition of

841 retrograde transport.

842 (A) Antibodies against ciliary markers acetylated $\alpha$-tubulin or IFT88 (magenta) and

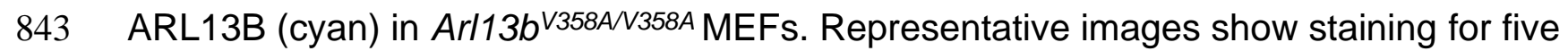

844 indicated ARL13B antibodies: (PT) polyclonal rabbit antibody against full-length human

845 ARL13B from ProteinTech, $(503,504,505)$ polyclonal rabbit sera from three distinct

846 rabbits raised against C-terminus of mouse ARL13B (amino acids 208-427) (Caspary et

847 al. 2007), and (NM) monoclonal mouse antibody against $C$ terminus of mouse ARL13B

848 from NeuroMab. Arl13 $b^{+/+}$and $A r l 13 b^{V 358 A++}$ show ciliary ARL13B staining. Table lists

849 ARL13B-positive cilia and the total number of cilia identified by acetylated $\alpha$-tubulin or

850 IFT88 antibody in parentheses. Cilia appear shorter in Arl13b $b^{V 358 A / V 358 A}$ cells (see Fig.

851 6). (B) IFT88 and (C) Gli3 (green) is enriched in the tips of cilia in Arl13b $b^{+/+}(+/+)$,

$852 A r l 13 b^{V 358 A /+}(A /+)$ and $\operatorname{Arl13} b^{V 358 A / V 358 A}(A / A)$ cells following ciliobrevin-D treatment.

853 Violin plots depict relative fluorescence of IFT88 and Gli3 at cilia tip to cell body with

854 number of cilia measured ( $n$ ) listed beneath each plot. (D \& E) Table lists ARL13B

855 (cyan) positive cilia (rabbit anti-ARL13B; ProteinTech or mouse anti-ARL13B;

856 NeuroMab) and the total number of cilia (acetylated $\alpha$-tubulin: magenta) examined in

857 control (DMSO) and ciliobrevin-D treated $(30 \mu \mathrm{M} \mathrm{CB})$ cell lines. Representative images

858 show staining for cilia and ARL13B. Staining of IFT88 and Gli3 analyzed by two-way

859 ANOVA and Sidak's multiple comparisons. $\left({ }^{* * *} p<0.001,{ }^{* * * *} p<0.0001\right)$. 


\section{Figure 4.}

ARL13B ${ }^{\mathrm{V} 358 \mathrm{~A}}$ mediates normal Shh signaling and neural tube patterning.

861 (A-I) Whole embryo and neural tube sections of somite-matched littermates at E9.5,

862 E10.5, and E12.5 stained with indicated markers of cell fate. Whole embryo scale bars:

$8632 \mathrm{~mm}$. (A'-l' \& A"-F”) Shh-dependent neural tube patterning at three separate time

864 points. Cell fate markers are listed above each image. All neural tube scale bars are 50

$865 \mu \mathrm{m}$. Neural tube patterning was examined in five embryos for each embryonic stage. E,

866 embryonic day.

\section{Figure 5.}

ARL13B ${ }^{\mathrm{V} 358 \mathrm{~A}}$ mediates normal ciliary enrichment of Shh components, but not ARL3 or INPP5E.

869 (A) Smo (green) enrichment in ventral neural tube cilia (acetylated $\alpha$-tubulin: magenta)

870 is normal in E10.5 embryos. Images are confocal projections. Scale bar is $25 \mu \mathrm{m} .(\mathrm{B}-\mathrm{H}$,

871 Top) Quantification of average fluorescence intensity in the tip of the cilium (Gli2, Gli3,

872 and Sufu) or the entire cilium (Ptch1, Smo, ARL3, and INPP5E) relative to background

873 level. Violin plots depict relative fluorescent intensity per cilium with number of cilia

874 examined below each plot. (B-H, Bottom) Representative images for each condition and

875 cell type with the cilia marker acetylated $\alpha$-tubulin (magenta) and indicated protein

876 (green). Wild type $(+/+)$, heterozygous $(A /+)$, homozygous $(A / A)$ and hennin $(h n n)$. Data

877 analyzed by one-way ANOVA and Tukey's multiple comparisons, except Smo data

878 analyzed by two-way ANOVA and 16 comparisons, corrected $p<0.003$ deemed

879 significant. ( $\left.{ }^{* *} p<0.01,{ }^{* * *} p<0.001,{ }^{* * * *} p<0.0001\right)$. 


\section{Figure 6.}

$\mathrm{ARL}^{13 B^{\mathrm{V} 358 \mathrm{~A}}}$ results in decreased ciliation rates and short cilia.

881 (A) Quantification of ciliation rates in all cell types; wild type $(+/+)$, heterozygous $(A /+)$,

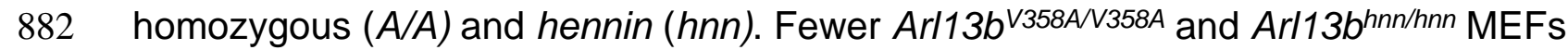

883 form cilia compared to $A r l 13 b^{+/+}$or $A r l 13 b^{V 358 A++}$ cells. (B) Quantification of axoneme

884 length as labeled by acetylated $\alpha$-tubulin (magenta) in indicated MEFs. Data are

885 presented as mean $(\mu \mathrm{m}) \pm$ standard deviation with the number of cilia measured per

886 genotype depicted at the base of each bar. Data analyzed by one-way ANOVA and

887 Tukey's multiple comparisons. $\left({ }^{*} p<0.05,{ }^{* *} p<0.01,{ }^{* * *} p<0.001,{ }^{* * *} p<0.0001\right)$

\section{Figure 7.}

888 Model comparing complete loss of ARL13B function to ciliary loss of ARL13B

889 function

890 Wildtype (left), Arl13 $b^{h n n h n n}$ (middle), and $A r l 13 b^{V 358 A / V 358 A}$ (right) cilia represented as two

891 halves. On the left half is the organization of Shh components in the presence of Shh

892 ligand and on the right half is the organization of ARL13B interactors ARL3 and

893 INPP5E. (A) ARL13B associates with the ciliary membrane. In the presence of Shh,

894 Ptch1 is removed from cilia and Smo is visibly enriched in cilia. Smo is activated which

895 promotes the processing of full-length Gli transcription factors into their activator forms

896 (GliA), that are shuttled out of the cilium to promote Shh-dependent gene transcription.

897 In addition, cilia proteins ARL3 and INPP5E are localized to the primary cilium. (B) In

898 Arl13 $b^{h n n / h n n}$ cells which are null for ARL13B, cilia are shorter than normal. Ciliary Ptch1

899 and Smo are visible, although Smo appears punctate instead of diffuse. In addition, loss 
900 of ARL13B decreases transcription of Shh-dependent genes due to lowered GliA.

$901 A r / 13 b^{h n n / h n n}$ cilia also display a failure of INPP5E and ARL3 to localize to the cilium.

902 Because $A R L 13 B$ is the GEF for ARL3, we speculate in this schematic that ARL3

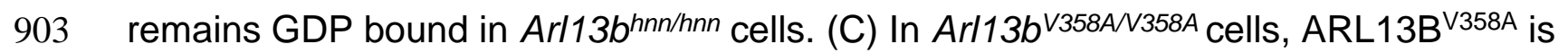

904 not detectable in cilia and appears diffuse within the cell body. Arl13b/358AV358A cilia, like

$905 A r l 13 b^{h n n / h n n}$ cilia, are shorter than wildtype. We observe normal Shh-dependent ciliary

906 Smo enrichment and normal Shh transcriptional output. However, ARL3 and INPP5E

907 are absent from cilia, indicating that ciliary ARL13B is required for ciliary residence of

908 these proteins.

\begin{tabular}{|c|c|c|c|c|c|}
\hline MICE & Sex & wildtype & V358A/+ & V358A/V358A & \\
\hline Het x Het & M (46.5\%) & 3 & 11 & 6 & \\
\hline Avg. Litter & $F(53.5 \%)$ & 6 & 8 & 9 & \\
\hline 7.3 & $\%$ of Total & 20.9 & 44.2 & 34.9 & $\chi^{2}=0.60$ \\
\hline Het x Hom & $M(60 \%)$ & - & 10 & 11 & \\
\hline Avg. Litter & $F(40 \%)$ & - & 6 & 8 & \\
\hline 7.5 & $\%$ of Total & - & 45.7 & 54.3 & $\chi^{2}=0.69$ \\
\hline Hom x Hom & M (47.4\%) & - & - & 9 & \\
\hline $\begin{array}{c}\text { Avg. Litter } \\
9.5\end{array}$ & $F(52.6 \%)$ & - & - & 10 & \\
\hline
\end{tabular}

Table 1.

909 Genotype of mice born to heterozygous and/or homozygous carrier parents. Data

910 analyzed by chi-squared test. 


\section{Figure 2 - Supplement 1}

911 Overexposure of $A r / 13 b^{1358 A / V 358 A}$ cilia in E10.5 neural tube reveals no clear

$912 \quad$ ARL13B $^{\mathrm{V} 358 \mathrm{~A}}$ presence in cilia.

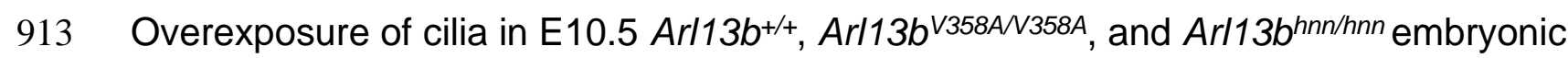

914 neural tube, stained for IFT88 and ARL13B (NeuroMab). The ARL13B channel was

915 overexposed for four seconds instead of one second.

\section{Figure 2 - Supplement 2}

916 Overexposure of $A r l 13 b^{V 358 A / V 358 A}$ cilia in MEFs reveals no clear ARL13B ${ }^{\mathrm{V} 358 \mathrm{~A}}$

917 presence in cilia.

918 (A) We identified acetylated $\alpha$-tubulin positive cilia and used the marker to outline the

919 area of the cilium. We quantified ARL13B immunofluorescence detected by Caspary lab

920 polyclonal anti-ARL13B antibody (Caspary et al. 2007) and used the same trace to

921 measure background levels in a different area of the cell body. (B) Arl13b

$922(A / A)$ and $A r l 13 b^{h n n / h n n}(h n n)$ MEFs treated with control or ciliobrevin-D 0.5\% FBS

923 Media. Samples were overexposed five times longer than normal, saturating the

924 detector in the ARL13B channel. We measured no difference in ciliary ARL13B

925 immunofluorescence between control and ciliobrevin-D treated $A r / 13 b^{V 358 A / V 358 A}$ and

926 Arl13b $b^{h n n / h n n}$ MEFs. Data presented as violin plots and analyzed by one-way ANOVA.

927 Respective number of cilia listed below each plot. Cilia that had ARL13B

928 immunofluorescent readings above background $\left({ }^{*}\right)$ are shown in panel D. (C)

929 Representative images of over exposed $A r l 13 b^{V 358 A / V 358 A}$ and $A r l 13 b^{h n n / h n n}$ MEFs in 
930 control and ciliobrevin-D treatment conditions. (D) Representative images of cilia with

931 ARL13B levels above background, marked by * in panel B.

932

Figure 3 - Supplement 1

933 Endogenous ARL13B is undetectable in the cell body of cilia mutant IFT172wim

934 cells.

935 Immunofluorescent detection of ARL13B (cyan; NeuroMab) and cilia marker acetylated

$936 \alpha$-tubulin (magenta) in wildtype, Arl13b $b^{\text {hnn }}$, IFT172wim, and IFT172wim Arl13b ${ }^{\text {hnn }}$ cell lines.

937 (A) In wildtype cells, ARL13B is detectable in the cilium under non-saturating conditions,

938 these parameters are kept constant across all samples. (B) In IFT172wim non-ciliated

939 cells, ARL13B protein is confined to the cell body, but is nearly undetectable by

940 standard immunofluorescence. (C-D) In Arl13b hnn and IFT172wim Arl13b ${ }^{\text {hnn }}$ cells, null for

941 Arl13b, any signal is due primary antibody background. At an exposure rate $4 \mathrm{x}$ above

942 normal the ARL13B signal saturates the detector in wildtype cells. In IFT172wim cells,

943 overexposure reveals no ARL13B positive stain that is above the background detected

944 in $A r l 13 b^{h n n}$ and IFT172wim Arl13b $b^{\text {hnn }}$ cells. Images taken at $40 x$. Scale bar is $5 \mu \mathrm{m}$.

945 Experiments repeated in duplicate and examined 4-6 fields of view per condition. 


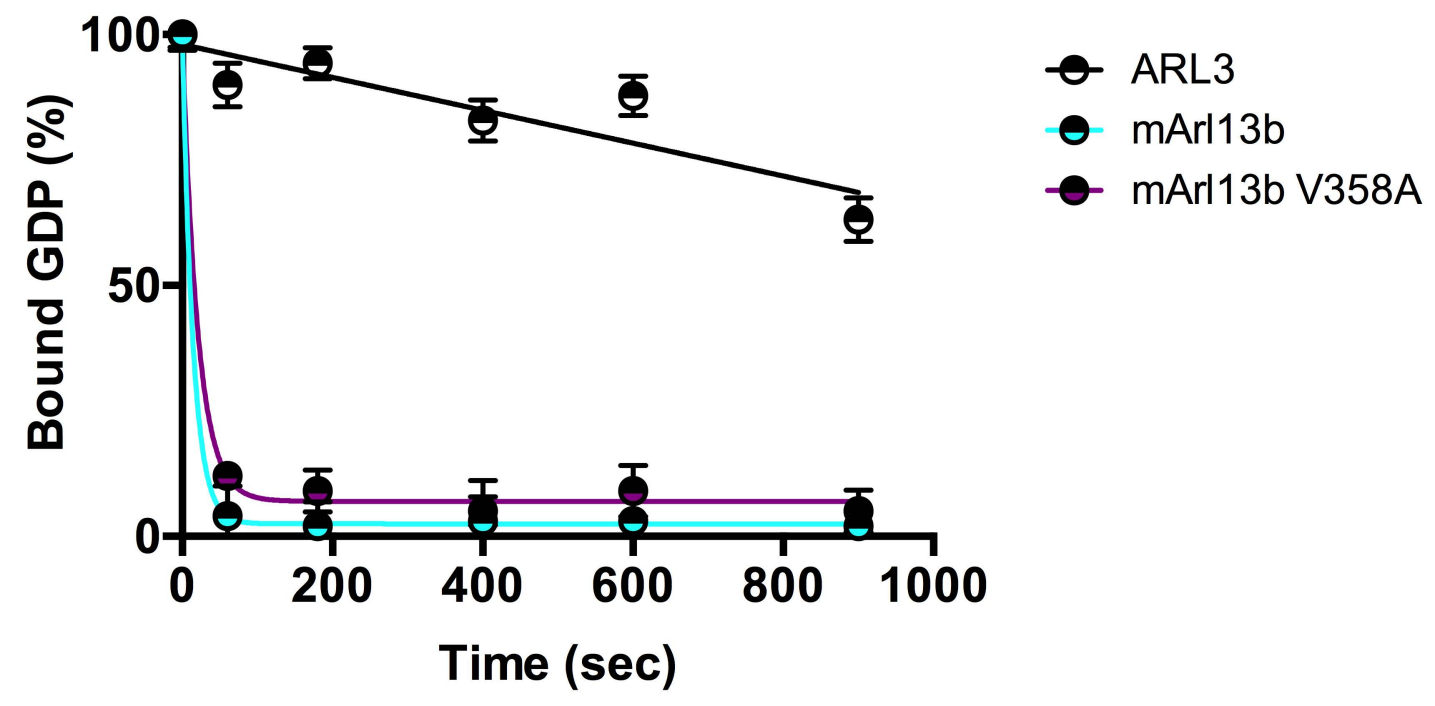




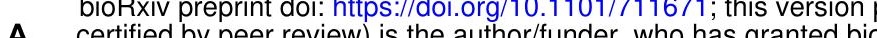
A certified by peer review) is the author/funder, who has granted bic Arl13b aCC-BY-NC-N

B

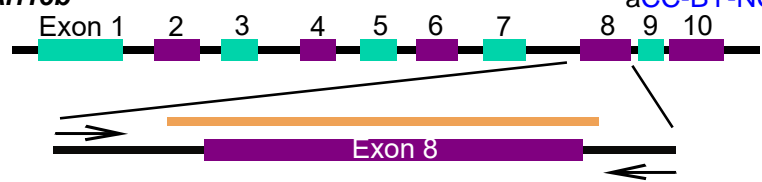

wildtype 5 '... AGT CAT CGG GTA GAA CCA GTC AAT ACA ...3' $\begin{array}{llllllllll}\ldots & \mathbf{S} & \mathbf{H} & \mathbf{R} & \mathbf{V} & \mathbf{E} & \mathbf{P} & \mathbf{V} & \mathbf{N} & \mathbf{T}\end{array}$

T-to-C 5'... AGT CAT CGG GCA GAA CCA GTC AAT ACA ...3' $\begin{array}{lllllllllll}\ldots & \mathbf{S} & \mathbf{H} & \mathbf{R} & \mathrm{A} & \mathbf{E} & \mathbf{P} & \mathbf{V} & \mathbf{N} & \mathbf{T} & \ldots\end{array}$
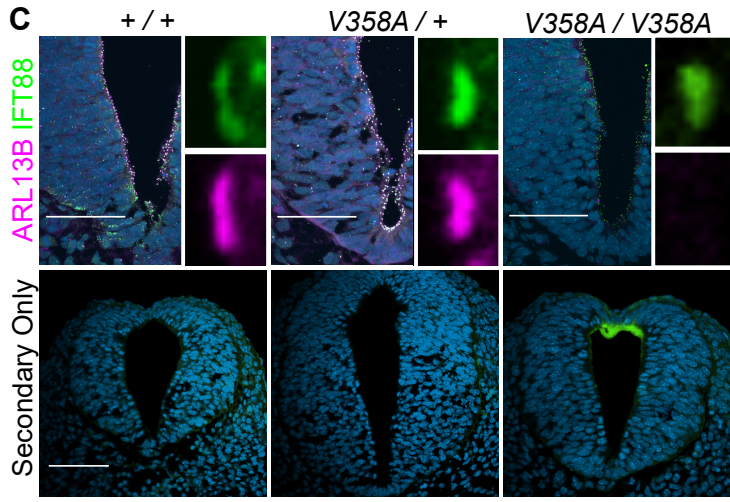

D

$75 \mathrm{Kd}$ -

Arl13b

${ }_{50 \mathrm{Kd}} \frac{\text { - }}{+/+} \frac{-}{A /+} \frac{-\square-\square}{A / A}$

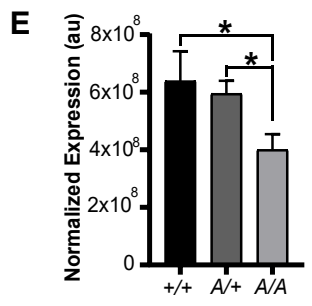




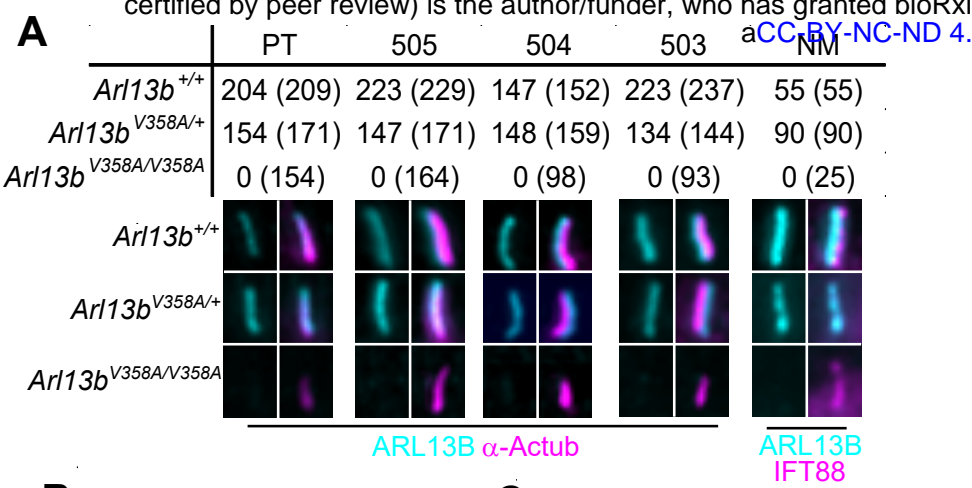

B

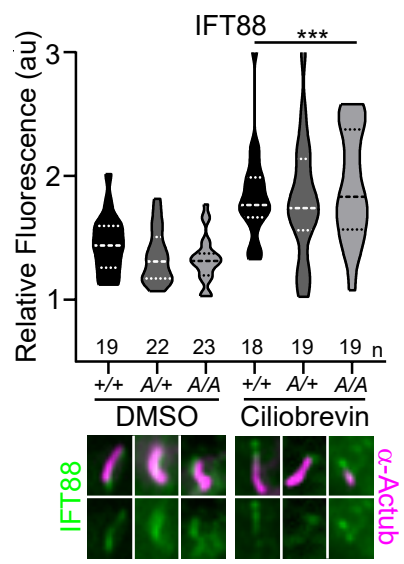

D

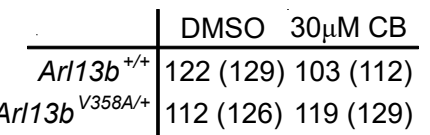

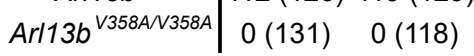

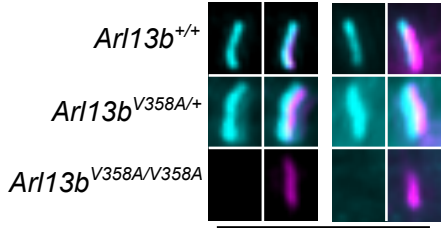

$\overline{\mathrm{ARL} 13 \mathrm{~B}} \alpha$-Actub
C

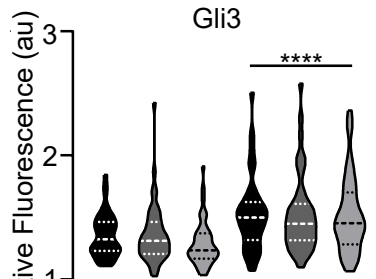

\begin{tabular}{l|ll} 
& DMSO & $30 \mu \mathrm{M} \mathrm{CB}$ \\
\hline Arr13b $^{+/}$ & $91(94)$ & $100(113)$
\end{tabular} Arl13b ${ }^{V 358 A++} 96(107) \quad 94$ (99)

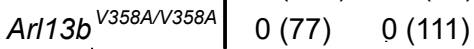

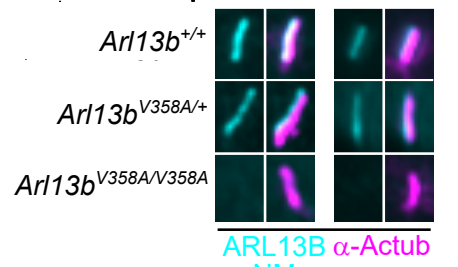




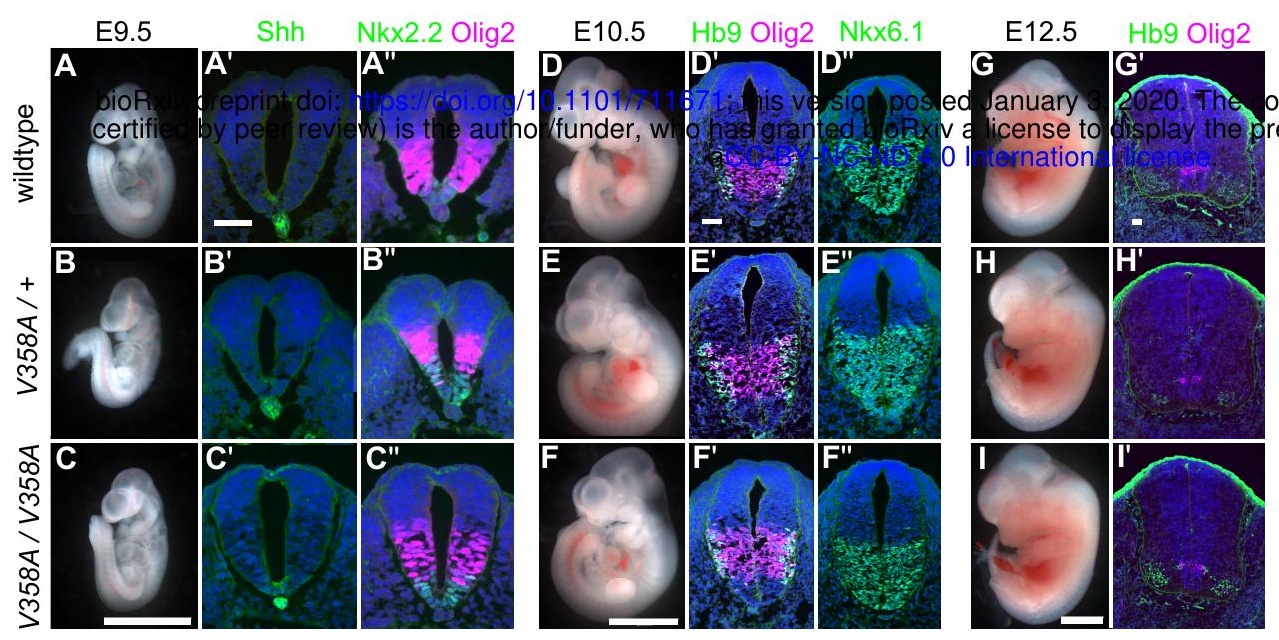


A $+/+\quad V 358 A /+V 358 A / V 358 A$

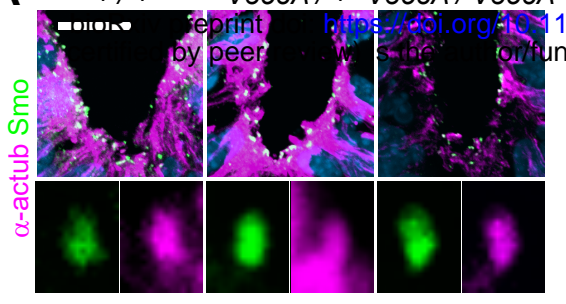

B Smoothened

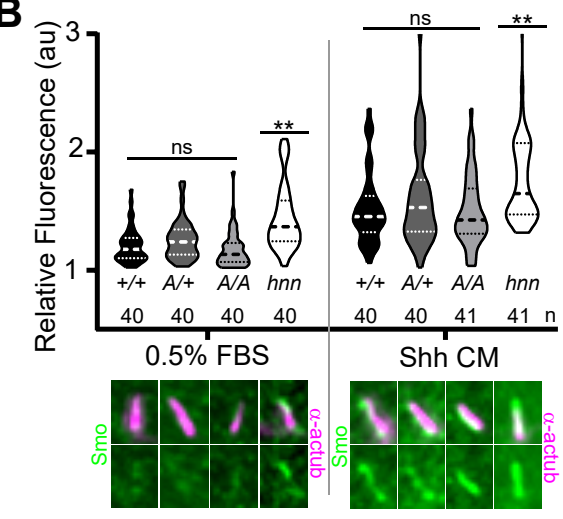

C

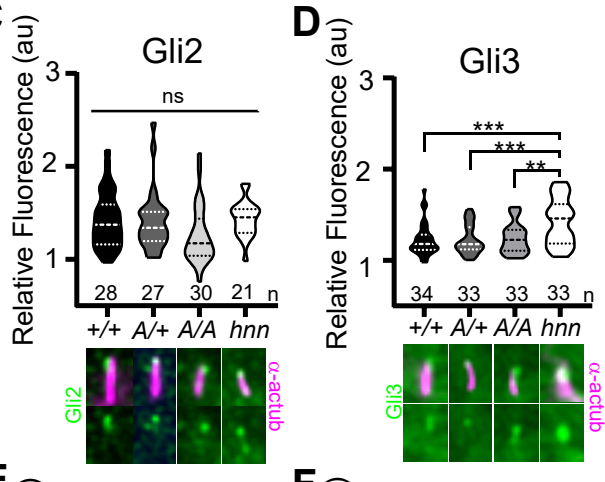

E
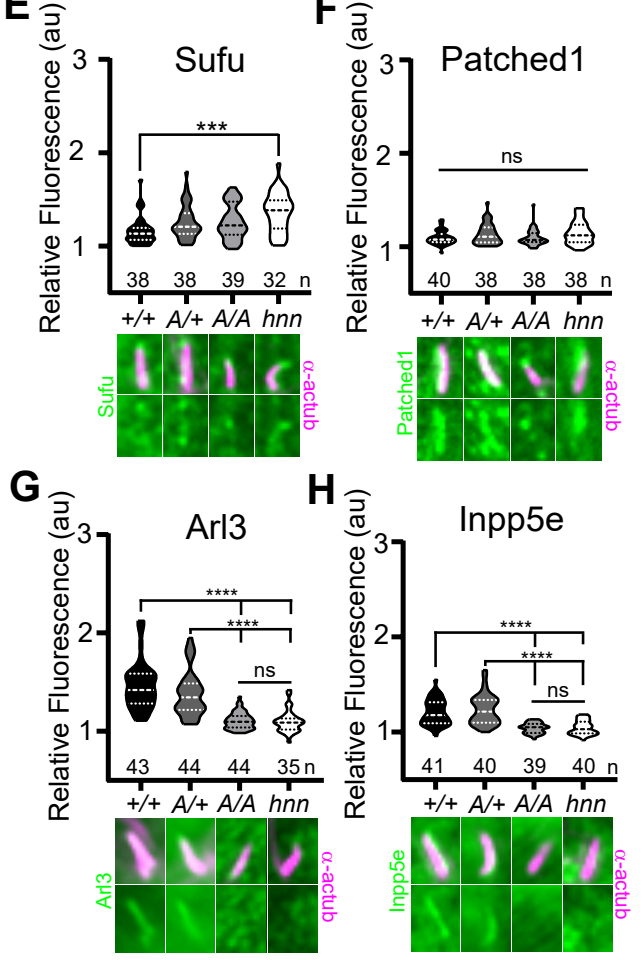
A

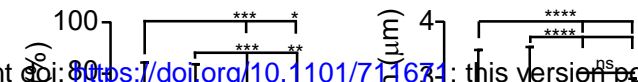

Leview) i de authorffunder,

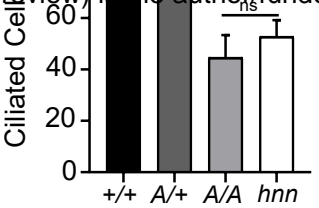

${ }_{\bar{\Phi}} 2 \mathrm{aC}$ EY-Nd-NP4.0

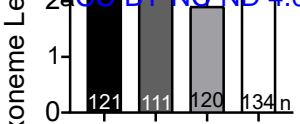

$+/+A /+A / A h n n$

$+/+A /+A / A$ hnn

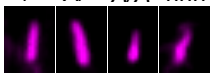


